\title{
Estado del ambiente de la Bahía San Julián, departamento Magallanes, Santa Cruz, Argentina
}

\author{
State of the environment of San Julián Bay, Magallanes Department, Santa Cruz, \\ Argentina
}

Blanca Pereyra Ginestar, Viviana Scavuzzo, Natalia Collm, Mario Baudino, Carla Moscardi brancasan2003@gmail.com.ar,vscavuzz@gmail.com,natas107@yahoo.com, mariobaudino@gmail.com,camoscardi@gmail.com

Instituto de Ciencias del Ambiente, Sustentabilidad y Recursos Naturales (ICASUR), Unidad Académica San Julián, Universidad Nacional de la Patagonia Austral Colón y Sargento Cabral - San Julián. Santa Cruz - Argentina

Recibido: 15/04/2019. Aceptado: 04/03/2020

\section{RESUMEN}

En la costa patagónica meridional, la bahía San Julián es un excelente espacio para las actividades recreativas y deportes náuticos. La zona de estudio abarca ambas márgenes, la costa occidental que tiene un mayor desarrollo de actividades urbanas y la costa oriental con menor actividad humana. Se releva parte de la información ambiental de la Bahía de San Julián con el propósito de evaluar su calidad ambiental a través de los sedimentos y el agua.

Los sedimentos mareales actúan como entrampadores de los metales pesados y en función de su concentración pueden constituir zonas de contaminación relevantes. Conjuntamente, se analizan la presencia de hidrocarburos totales en agua. Se han realizado análisis bacteriológicos en el agua marina y se han registrado los parámetros fisico-químicos de la misma. Los censos de aves marinas y playeras por especie completan la investigación. Los resultados obtenidos indican que los valores de concentración para el $\mathrm{Pb}, \mathrm{Cu}$ y $\mathrm{Zn}$ están por debajo de los rangos máximos permitidos de acuerdo a la normativa nacional e internacional vigente. No se ha detectado la presencia de hidrocarburos totales en aguas. En todas las estaciones, el muestreo bacteriológico acusó la presencia de bacterias coliformes totales especialmente en las zonas con impacto antrópico directo por la descarga de efluentes cloacales. Este tipo de disturbios influyen sobre la diversidad de aves ya que el gradiente basado en la disminución en la riqueza y un aumento en la abundancia, ocurre en la zona de los efluentes cloacales, especialmente en las especies generalistas y omnívoras como Larus dominicanus. La información está sistematizada en un SIG a partir del cual se generaron mapas temáticos.

Palabras clave: metales pesados; agua; bacteriología; hidrocarburos; aves.

\begin{abstract}
On the southern Patagonian coast, the bay of San Julián is an excellent space for recreational activities and water sports. The study area covers both margins, the western coast that has a greater development of urban activities and the eastern coast with less human activity. The objective is evaluate its environmental quality through sediments and water. Tidal sediments act as heavy metal traps and, depending on their concentration, can constitute relevant
\end{abstract}


pollution zones. Together, the presence of total hydrocarbons in water is analyzed. Bacteriological analyzes have been carried out in the seawater and the physico-chemical parameters of the same have been recorded. Censuses of seabirds and t-shirts by species complete the investigation. The results obtained indicate that the concentration values for $\mathrm{Pb}$, $\mathrm{Cu}$ and $\mathrm{Zn}$ are below the maximum permitted ranges according to current national and international regulations. The presence of total hydrocarbons in waters has not been detected. In all the stations, bacteriological sampling showed the presence of total coliform bacteria specially in areas that suffer direct anthropic impact by the discharge of sewage effluents. This type of disturbance influences the diversity of birds since the gradient based on the decrease in richness and an increase in abundance occurs in the area of sewage effluents, especially in generalist and omnivorous species such as Larus dominicanus. The information is systematized in a GIS, from which thematic maps were generated.

Keywords: heavy metals; water; bacteriology; hydrocarbons; birds.

\section{INTRODUCCIÓN}

El objetivo general de este trabajo, es relevar parte de la información ambiental de la Bahía de San Julián con miras a la evaluación de la calidad ambiental de la misma. Por ello, es importante caracterizar los sedimentos y el agua. De esta manera, se ha enfatizado en conocer la distribución de los elementos pesados en los sedimentos intermareales y su geoacumulación, la determinación de hidrocarburos totales en agua así como la caracterización fisicoquímica y el análisis bacteriológico de la misma.

Los sedimentos mareales actúan como entrampadores de los metales pesados y en función de su concentración pueden constituir zonas de contaminación relevantes.

En el agua marina, se registraron los parámetros fisico-químicos, se determinó la presencia de hidrocarburos totales y se realizaron análisis bacteriológicos.

Los censos de aves marinas y playeras por especie completan la investigación.

Los resultados obtenidos en los sedimentos indican que los valores de concentración de algunos metales pesados como el $\mathrm{Pb}, \mathrm{Cu}$ y $\mathrm{Zn}$ están por debajo de los límites máximos permitidos de acuerdo a la normativa nacional e internacional vigente. Por su parte, las concentraciones del $\mathrm{Cd}$ y el $\mathrm{Hg}$ están por debajo del límite de detección del método por lo cual se los considera Ausentes en el sitio de estudio.

El índice de geoacumulación - IGeo - señala un ambiente "no contaminado a moderadamente contaminado" y el índice de contaminación urbano industrial - CUI -

En cuanto a los resultados obtenido en agua marina, no se detectó la presencia de hidrocarburos totales ya que los valores registrados están por debajo del límite de detección del método. Sin embargo, en el efluente, se detectó su presencia con un valor inferior al de la normativa tomada como referencia.

El muestreo y análisis bacteriológico acusó la presencia de bacterias coliformes totales en todas las estaciones. No obstante, las zonas que sufren impacto antrópico directo por la descarga de efluentes cloacales, los valores registrados son superiores a los normados por la legislación vigente lo cual requiere especial atención.

Este tipo de disturbios influyen sobre la diversidad de aves ya que el gradiente basado en la disminución en la riqueza y un aumento en la abundancia, ocurre en la zona de los efluentes cloacales, especialmente en las especies generalistas y omnívoras como Larus dominicanus. La información está sistematizada en un sistema de información geográfica - SIG - para generar los mapas temáticos que ilustran esta publicación. 
En cuanto a la estructura del trabajo se ha seguido la conformación normal donde se dan a conocer los distintos marcos de referencia, histórico, conceptual y normativo seguido de la metodología utilizada y los resultados obtenidos. Completan el trabajo las conclusiones y consideraciones pertinentes, junto con la bibliografía consultada.

\section{ESTRUCTURA DEL DOCUMENTO}

\subsection{Marco de referencia}

\section{Marco teórico}

La localidad de Puerto San Julián, cabecera del Departamento Magallanes, se sitúa sobre la margen occidental de la bahía homónima. La bahía de San Julián es un ecosistema complejo con un importante sector interno de marismas y un sector externo con islas en las que se hallan colonias de aves marinas, principalmente pingüinos (Spheniscus magellanicus) y cormoranes (Phalacrocorax albiventer, Ph. magellanicus, Ph. olivaceus) y abundantes poblaciones intermareales de mejillones. La presencia de variados ambientes alberga numerosas especies de la fauna patagónica que, como reservorios de vida silvestre, constituyen la principal atracción turística de la región. El arribo de turistas es marcadamente estacional y se concentra en primavera y verano, debido principalmente a las condiciones climáticas más benignas y la presencia, particularmente de pingüinos y toninas overa Constituye un excelente espacio para las actividades turísticas, portuarias y recreativas como deportes náuticos, el canotaje, windsurf o la navegación a vela en el extenso espejo de agua que se forma, así como el desarrollo la acuicultura y distintos trabajos de investigación y conservación que se llevan a cabo (Propatagonia UNPA-UARG, 2007).

Otros de los atractivos turísticos de la localidad de Puerto San Julián es la visita al "Circuito Costero". Los procesos geomorfológicos de la costa como la energía de las olas y las corrientes de mareas actúan sobre las rocas y sedimentos, los que producen los cambios morfológicos de los paisajes costeros que generan geoformas de acumulación, erosión, remoción en masa (Scavuzzo y Pereyra G, 2016).

La bahía es una albufera con una amplia llanura de fango intermareal, en parte vegetada por Sarcocornia sp. y en parte con predominancia de cantos rodados de origen fluvio glaciar, relictos de procesos glaciogénicos del Pleistoceno alto, y una densa red de canales de marea, muy ramificada (Panza et al, 1994). Se comunica con el litoral Atlántico mediante un canal principal estrecho. Tiene su entrada entre el cabo Curioso y la punta Desengaño, su longitud máxima es de $22 \mathrm{~km}$ con un ancho que varía entre 1 y $8 \mathrm{~km}$. Termina en un amplio saco al sur, el cual está expuesto normalmente durante la bajamar. Las mareas son macrotidales ya que su rango oscila entre los $6 \mathrm{~m}$ y $9 \mathrm{~m}$. En la bahía se destacan las amplias planicies de mareas, playas, cordones litorales y acantilados, entre otros. La baja energía del ambiente marino genera la acumulación de sedimentos fango arcillosos susceptibles de concentrar metales pesados.

En la parte interior de la bahía, se encuentran los bancos Cormorán, Justicia y Mina.

En la región, domina el clima templado frío y semiárido con precipitaciones que se concentran preferentemente en el período invernal con una media anual de alrededor de 200 $\mathrm{mm}$ (Soto, 2004).

El marcado déficit hídrico regional determina las condiciones de la estepa subarbustiva asociados con gramíneas altas con profusa abundancia de aves que se desarrolla aledaña a la costa y en las islas interiores.

Las acciones que implican un adecuado manejo de los recursos naturales y el cuidado del ambiente, en particular aquellas relacionadas con el mantenimiento de áreas naturales de 
reserva, promueven el turismo asociado a la observación de especies faunísticas o ecosistemas singulares y en consecuencia redundan en un mayor ingreso de turistas y visitantes a la localidad.

\section{Marco histórico}

La Bahía San Julián ha sido objeto de investigaciones de carácter extensivo desarrolladas sobre la zona costera patagónica, pudiéndose citar a Tagliorette y Losano, 1996; Esteves et al. (2007); Gil et al., (1996), listado de áreas protegidas Yorio et al., (1998); ubicación y estudios ecológicos de colonias reproductivas de aves marinas (Boersma, et al., 2009; Collm et al., 2008; Frere y Gandini,1998; Millones y Frere, 2012; Schweitzer et al. (2006), Schweitzer (2007), Wilson et al., 2001; Frere y Gandini, 1998; Gil et al., 1997; Zaixso et al. (2007), Kokot et al. (2013), entre otras.

Durante 1995, Gil et al. (1996) realizaron una campaña de muestreo de metales pesados a lo largo de la costa atlántica. Desde la desembocadura de Río Colorado en el norte hasta Punta Loyola en el sur entre las cuales se encuentra San Julián.

Investigaciones relacionadas en el área de estudio, aportan conocimientos acerca de la estructura del ecosistema a través de la descripción de los factores bióticos y abióticos del ambiente marino, terrestre y socioeconómico, y de manera específica, Zaixso (2007) "Estudio de base para una gestión integrada de la bahía de San Julián”. Por su parte, el trabajo de Kokot et al. (2013) comunica sus resultados respecto a los aspectos y procesos geomorfológicos de la costa sanjulianense.

En el proyecto de investigación "Estudio de la situación ambiental a través de la medición de la calidad de agua y sedimentos de la Bahía San Julián y su zona de influencia, provincia de Santa Cruz." 29/D 063, que se desarrolló durante el periodo 2015 - 2016, el objetivo principal fue la actualización de la información ambiental de la bahía de San Julián y su área de influencia con estudios de detalle sobre la calidad de agua y la medición de contenidos de metales pesados en los sedimentos de la planicie mareal (Pereyra G. et al. 2015, 2016; Becker y Collm, 2015). La investigación del área tuvo continuidad en el proyecto "Zonificación ambiental a partir de la distribución de la concentración metales pesados, hidrocarburos y aguas en la bahía San Julián, departamento Magallanes, Santa Cruz" 29/D 075 desarrollado en el período 2017 - 2018 en el cual se analizó la presencia de hidrocarburos totales y el análisis bacteriológico en agua (Pereyra G. et al. 2017). Ambos proyectos fueron financiados por la UNPA.

\section{Marco conceptual}

Para reconocer el grado de contaminación por metales e hidrocarburos en una determinada zona es necesario establecer el valor natural de base en todo el sitio. Los sedimentos pueden actuar como portadores y posibles fuentes de contaminación porque los metales pesados no se quedan permanentemente en ellos y pueden ser liberados a la columna del agua por cambios en las condiciones ambientales tales como $\mathrm{pH}$, potencial redox, oxígeno disuelto, entre otras (Szefer et al., 1998). Bajo estas circunstancias, el análisis de metales pesados en sedimentos permite reconocer alteraciones ambientales, vía enriquecimiento de algunos de ellos en el sedimento y detectar la contaminación que puede escapar al análisis de las aguas y también proporciona información acerca de las zonas críticas del sistema acuático.

Aunque algunos metales pesados entre ellos el mercurio, el cadmio y el plomo, están considerados como contaminantes altamente peligrosos, el cobre y el cinc, si bien esenciales para los organismos vivos, también resultan tóxicos cuando se superan ciertas 
concentraciones umbrales. Estos metales son elementos recurrentes en los problemas derivados de la contaminación ambiental en las zonas cercanas a asentamientos humanos.

Los estudios del enriquecimiento, disponibilidad y distribución de los metales pesados en los sedimentos de ambientes acuáticos son temas de interés relevante por la capacidad del sedimento a concentrar e integrar a los ecosistemas los metales disueltos y convertirse en zonas potenciales de riesgo ambiental (De Gregori et al, 1996). Es por ello, que se mide la concentración de estos metales pesados en los sedimentos mareales de la bahía.

\section{Marco Normativo}

En este apartado se enumeran las normas y reglamentaciones, tanto a nivel regional, nacional e internacional que se han tomado en consideración para referenciar los valores obtenidos en los estudios llevados a cabo en los sedimentos y el agua marina de la Bahía San Julián.

\section{Normativa para Sedimentos}

Como referencia normativa a tener en cuenta para comparar los valores encontrados, se han tomado normas nacionales e internacionales: canadienses y españolas.

\section{Normativa nacional}

Argentina

Se han tomado como referencia la legislación actualmente en vigencia y existente a nivel provincial y nacional.

La Ley 24585 denominada "De la protección ambiental para la actividad minera" es quien regula los estándares ambientales. El Anexo IV de la misma consta de siete tablas que indican la concentración máxima para cada elemento químico que deben tener el agua, suelo y aire para que sea ambientalmente aceptable de acuerdo al uso de cada recurso (tabla III.7 del Anexo III).

\section{$\underline{\text { Normativa internacional }}$}

\section{Canadá}

El Grupo de tareas sobre normas de calidad del agua del Consejo Canadiense de Ministros de Medio Ambiente (CCME, 2002) desarrolló concentraciones químicas recomendadas para apoyar y mantener la vida acuática asociada con los sedimentos del lecho. Estos valores se derivan de la información científica disponible sobre los efectos biológicos de los productos químicos asociados a los sedimentos, destinados a apoyar el funcionamiento de ecosistemas saludables. El protocolo de directrices de calidad de sedimentos se basa en el enfoque del Programa de estado y tendencias nacionales y en el enfoque de prueba de toxicidad de sedimentos enriquecidos.

PEL: Los niveles de efectos probables (PEL -Probable Effects Level-) corresponden a concentraciones por encima de las cuales se encuentran con frecuencia efectos biológicos adversos.

ERB y ERM: Criterios de calidad para los sedimentos propuestos por Long et al (1995) basado en el potencial de inducir efectos tóxicos en los organismos marinos, para lo que han 
definido dos valores: ERB y ERM. Los Valores de ERB (Efectos de Rango Bajo) indican concentraciones por debajo de las cuales rara vez se producen efectos adversos, y los valores de ERM (Efectos de Rango Medio). representan concentraciones por encima de las que con frecuencia se producen efectos adversos

\section{España}

NIVEL 1 y NIVEL 2: Recomendaciones del Centro de Estudios y Experimentación de Obras Públicas (CEDEX, 1994) para la gestión de material dragado en los puertos españoles, muy utilizadas por los investigadores españoles en los trabajos sobre sedimentos.

En la Tabla 1 se detallan los valores referenciales para la concentración de los metales pesados estudiados con normativa tanto nacional como internacional - canadiense y española expresados en $\mathrm{mg} / \mathrm{Kg}$.-

Tabla 1: Normativa nacional e internacional tomadas como referencia.

\begin{tabular}{c|ccc|c|c} 
Normativa & \multicolumn{3}{|c|}{ Canadiense } & Española & Argentina \\
\hline Metales & PEL & ERB & ERM & NIVEL 1 & SUELOS \\
Cu & 41,6 & 34,0 & 270,0 & 100,0 & 150,0 \\
Pb & 112,0 & 46,7 & 218,0 & 120,0 & 375,0 \\
Zn & 271,0 & 150,0 & 410,0 & 500,0 & 600,0
\end{tabular}

\section{Normativa para Aguas:}

\section{$\checkmark$ Microbiológico}

Como marco de referencia para tener en cuenta para compararlo con los resultados obtenidos, se han tomado leyes y normas provinciales y regionales (Tabla 2).

La ley $\mathrm{N}^{\circ}$ 2658, de Evaluación de Impacto Ambiental de la provincia de Santa Cruz, es la norma provincial vigente que regula los límites de descarga en agua de mar de efluentes según cuerpo receptor. Anexo I: Parámetros de calidad de las descargas en agua y suelo:

límites admisibles (Marco legal Santa Cruz, 2003).

La normativa de la provincia de Chubut (Ley 1503) establece los límites de calidad de agua para los cuerpos receptores según la potencialidad de uso (Marco legal Chubut, 1977).

Tabla 2: Marco normativo de referencia de Santa Cruz y Chubut para microbiología.

\begin{tabular}{|c|c|c|c|}
\hline \multirow{2}{*}{$\begin{array}{c}\text { Límite de descarga en } \\
\text { Agua de Mar } \\
\text { Ley 2658 Pcia. de Santa Cruz } \\
\text { Decreto A007-06 } \\
\text { Anexo I: } \\
\text { Coliformes Fecales }\end{array}$} & \multicolumn{3}{|c|}{$\begin{array}{l}\text { Calidad de agua de cuerpos receptores } \\
\text { Ley } 1503 \text { Pcia. de Chubut - Decr. 2099/77 - Anexo III - Coliformes }\end{array}$} \\
\hline & $\begin{array}{c}\text { Recreo/Baño y natación } \\
\text { - Agua salada }\end{array}$ & $\begin{array}{c}\text { Navegación deportiva y } \\
\text { pesca - Agua salada }\end{array}$ & $\begin{array}{c}\text { Vida acuática } \\
\text { (peces/aves) }\end{array}$ \\
\hline$<20.000 / 100 \mathrm{ml}$ & $1.000 / 100 \mathrm{ml}$ & $10.000 / 100 \mathrm{ml}$ & $100.000 / 100 \mathrm{ml}$ \\
\hline
\end{tabular}

\section{Hidrocarburos}

La ley N ${ }^{\circ} 2658$, de Evaluación de Impacto Ambiental de la provincia de Santa Cruz, es la norma provincial que regula los límites admisibles de descarga en agua de mar de hidrocarburos según cuerpo receptor (Marco legal Santa Cruz op.cit.) (Tabla 3). 
Tabla 3: Marco normativo de referencia de Santa Cruz para hidrocarburos.

\begin{tabular}{|l|c|}
\hline Santa Cruz & \\
\hline $\begin{array}{l}\text { Límite de descarga en Agua de Mar. Ley 2658. Santa Cruz Decreto A007- 06. } \\
\text { Anexo I: Hidrocarburos }\end{array}$ & $<=\mathbf{2 0 m g / l}$ \\
\hline
\end{tabular}

\subsection{Resultados, análisis y discusión}

\section{Materiales y métodos}

\section{Estaciones de muestreo}

Se realizaron muestreos en sedimentos intermareales para determinar la concentración de metales totales y en agua marina para determinar la bacteriología, características fisicoquímicas y la concentración de hidrocarburos, como se detalla en la Tabla 1. Se han tomado muestras de sedimentos en trece puntos en el interior de la BSJ en ambas márgenes, dos puntos en mar abierto (I y II) y un punto en la descarga de arroyos.

Tabla 4: Estaciones de muestreo en la Bahía San Julián

\begin{tabular}{|c|c|c|c|c|c|c|c|}
\hline \multirow{2}{*}{$\begin{array}{l}\text { Estación } \\
\text { - E - }\end{array}$} & \multirow{2}{*}{ Lugares } & \multirow{2}{*}{$\begin{array}{c}\text { Sedimentos } \\
\text { Metales }\end{array}$} & \multicolumn{4}{|c|}{ Agua } & \multirow{2}{*}{$\begin{array}{l}\text { Biota } \\
\text { Aves }\end{array}$} \\
\hline & & & Bacteriol. & Físico/Qco & HHCC & Metales & \\
\hline 1 & I - Playa La Mina & $\mathrm{X}$ & & $\mathrm{X}$ & & & \\
\hline 2 & Punta Peña & $\mathrm{X}$ & $\mathrm{X}$ & $\mathrm{X}$ & & & \\
\hline 3 & Paso de la Isla Cormorán & $\mathrm{X}$ & $\mathrm{X}$ & & & & $\mathrm{X}$ \\
\hline 4 & $\begin{array}{l}\text { Efluente Marea baja Intermareal } \\
\text { fango-arenoso }\end{array}$ & $\mathrm{X}$ & $\mathrm{X}$ & $\mathrm{X}$ & & & \\
\hline 5 & Efluente Marea Alta & $\mathrm{X}$ & $X$ & $\mathrm{X}$ & $\mathrm{X}$ & & $\mathrm{X}$ \\
\hline 20 & \begin{tabular}{|l}
$\begin{array}{l}\text { Cámara descarga efluente } \\
\text { cloacal- Planta Tratamiento }\end{array}$ \\
\end{tabular} & & $\mathrm{X}$ & $\mathrm{X}$ & $\mathrm{X}$ & $X$ & \\
\hline 6 & Punta Caldera - Muelle nuevo & $\mathrm{X}$ & $\mathrm{X}$ & $\mathrm{X}$ & $\mathrm{X}$ & & $\mathrm{X}$ \\
\hline 7 & Club Náutico & $\mathrm{X}$ & $\mathrm{X}$ & $\mathrm{X}$ & $\mathrm{X}$ & & \\
\hline 8 & Cascada - agua de mar & $\mathrm{X}$ & $\mathrm{X}$ & $\mathrm{X}$ & $\mathrm{X}$ & & $\mathrm{X}$ \\
\hline 9 & Saco de la bahía & $\mathrm{X}$ & & & & & \\
\hline 24 & Efluente Cascada /Alberdi & & $\mathrm{X}$ & $\mathrm{X}$ & $\mathrm{X}$ & & \\
\hline 25 & Canal marea Cascada & $\mathrm{X}$ & $\mathrm{X}$ & & & & $\mathrm{X}$ \\
\hline 28 & a. Arroyo Sam & $\mathrm{X}$ & & & & & \\
\hline 22 & Frente al Pueblo - Península & $\mathrm{X}$ & $\mathrm{X}$ & $\mathrm{X}$ & $\mathrm{X}$ & & \\
\hline 21 & Rincón - Península & $\mathrm{X}$ & $\mathrm{X}$ & & & & \\
\hline 18 & Caldera baja & $\mathrm{X}$ & $\mathrm{X}$ & & & & \\
\hline 23 & II- Playa Los Instalados & $\mathrm{X}$ & $\mathrm{X}$ & & & & \\
\hline
\end{tabular}

Asimismo, se realizó la observación de aves costeras en las diferentes estaciones. Estos son los primeros estudios exhaustivos sobre la concentración total de metales pesados en sedimentos marinos, presencia de hidrocarburos totales y análisis bacteriológicos de aguas realizados en la localidad. 
Los muestreos se llevaron a cabo en campañas entre los años 2015 al 2018. Todas las estaciones de muestreo han sido georreferenciadas.

En la Tabla 4 y Fig. 1 se señalan los análisis realizados y la ubicación de las estaciones de muestreo, respectivamente. Es esencial estos estudios a fin de conocer el actual estado ambiental y cómo conservar el mismo.

La metodología específica del muestreo, procesamiento y análisis para cada componente ambiental analizado y por cada parámetro se describe a continuación.

Figura 1: Ubicación de las estaciones de muestreo en la Bahía San Julián. Imagen satelital de la BSJ.
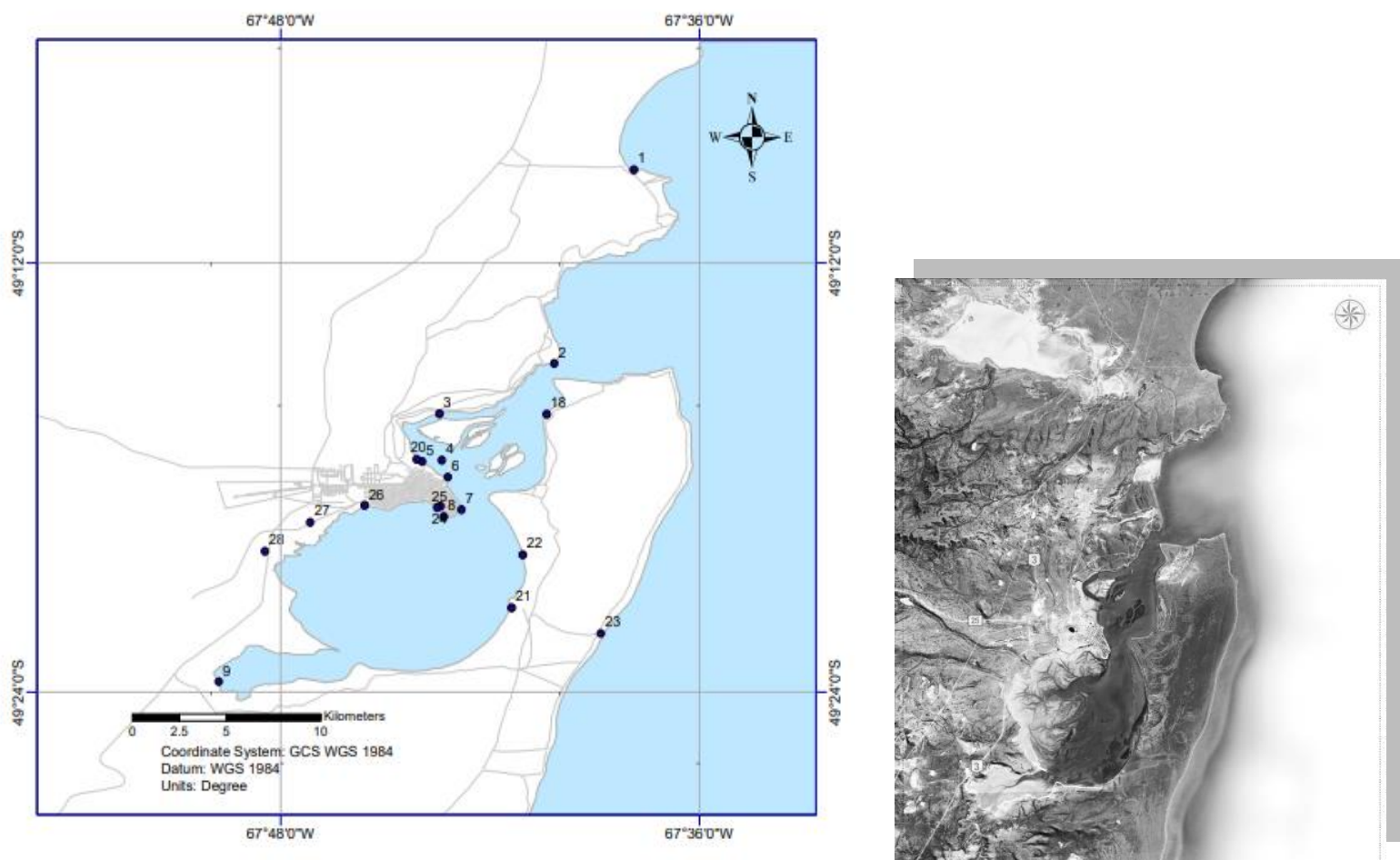

\section{Metodología de muestreo}

\section{$\underline{\text { Sedimentos }}$}

\section{Metales pesados:}

En cada muestreo, se extrajo el sedimento, más fino disponible en los primeros $15 \mathrm{~cm}$ de profundidad. Las muestras de $1 \mathrm{~kg}$ fueron embolsadas etiquetadas y enviadas al laboratorio.

El muestreo se realizó con una frecuencia anual. Se determinó la concentración total de metales pesados. Se aplicó la técnica de digestión multiácida y la lectura se realizó con el equipo de plasma de acoplamiento inductivo ICP - OES de 39 elementos. El procesamiento de las muestras se llevó a cabo en un laboratorio externo.

Se han determinado las concentraciones totales de cadmio, cobre, mercurio, plomo y zinc. En la Tabla 5 se muestran los límites de detección del método utilizado para su medición. 
Tabla 5: Límites de detección del método

\begin{tabular}{c|c} 
Elemento & Limite de detección $(\mathrm{mg} / \mathrm{Kg})$ \\
\hline $\mathrm{Cd}$ & 0,003 \\
$\mathrm{Cu}$ & 0,009 \\
$\mathrm{Hg}$ & 0,030 \\
$\mathrm{~Pb}$ & 0,084 \\
$\mathrm{Zn}$ & 0,006
\end{tabular}

Con estos datos se han calculado dos índices: el de Geoacumulación y el Urbano-Industrial

$\checkmark$ Índice de Geoacumulación - IGeo:

Este índice es ampliamente utilizado para la evaluación del grado de contaminación por metales pesados en ambientes impactados. Fue definido por Müller (1979) como:

$$
\mathrm{IGeo}=\log _{2}(\mathrm{Cn} / 1,5 \mathrm{Bn})
$$

Donde $\quad \mathrm{Cn}=$ concentración del metal en este estudio en $\mu \mathrm{g} \mathrm{g}^{-1}$;

$\mathrm{Bn}=$ valor geoquímico de background en $\mu \mathrm{g} \mathrm{g}^{-1}$, o valores preindustriales correspondiente a ambientes no contaminados.

El valor 1.5 representa las posibles variaciones en el nivel de base del metal medido en el ambiente, y se utiliza como un factor de corrección de una eventual influencia antrópica en el cálculo (Buccolieri et al., 2006).

El IGeo tiene 7 grados como se detalla en la tabla 6.

Tabla 6: Clasificación del Índice de Geoacumulación de acuerdo a Müller (1979)

\begin{tabular}{|c|c|l|}
\hline Valor del IGeo & Clases del IGeo & \multicolumn{1}{|c|}{ Grado de contaminación } \\
\hline 0 & Igeo $<0$ & No contaminado \\
\hline 1 & $0<$ Igeo $<1$ & No contaminado a moderadamente contaminado \\
\hline 2 & $1<$ Igeo $<2$ & Moderadamente contaminado \\
\hline 3 & $2<$ Igeo $<3$ & De moderado a fuertemente contaminado \\
\hline 4 & $3<$ Igeo $<4$ & Fuertemente contaminado \\
\hline 5 & $4<$ Igeo $<5$ & De fuertemente a extremadamente contaminado \\
\hline 6 & $5<$ Igeo $<6$ & Extremadamente contaminado \\
\hline
\end{tabular}

Índice de contaminación Urbano Industrial - C.U.I. -

Este índice definido por Papakostidis et al. (1975) corresponde a la sumatoria de las concentraciones de los metales pesados plomo, cobre y zinc en partes por millón:

$$
\text { C.U.I. }=[\mathrm{Pb}]+[\mathrm{Cu}]+[\mathrm{Zn}]
$$

$\mathrm{El} \mathrm{Pb}, \mathrm{Cu}, \mathrm{y} \mathrm{Zn}$ son considerados indicadores clásicos de la actividad humana porque ellos provienen de fuentes urbanas e industriales (Amat Infante et al., 2002).

\section{$\underline{\text { Aguas }}$}

Caracterización de las propiedades físicas del agua 
Se tomaron in situ los parámetros físicos del agua $\mathrm{pH}$, temperatura, conductividad eléctrica y salinidad utilizando la sonda multiparamétrica U10-Horiba (Figura 2 y 3 ).

\section{Muestreo bacteriológico}

Se tomaron muestras de agua de $500 \mathrm{~cm}^{3}$, en recipientes estériles, con la inmediata conservación en frío hasta el procesamiento que se realizó en el laboratorio de la Unidad Académica San Julián de la Universidad Nacional de la Patagonia Austral. En cada sitio, el muestreo se realizó por triplicado, durante el otoño y la primavera.

Figura.2: El grupo de investigación realiza la toma de muestras de aguas en la estación 2 Punta Peña. En la estación 6 Punta Caldera - Muelle nuevo se miden los parámetros físicoquímicos del agua con el Horiba.
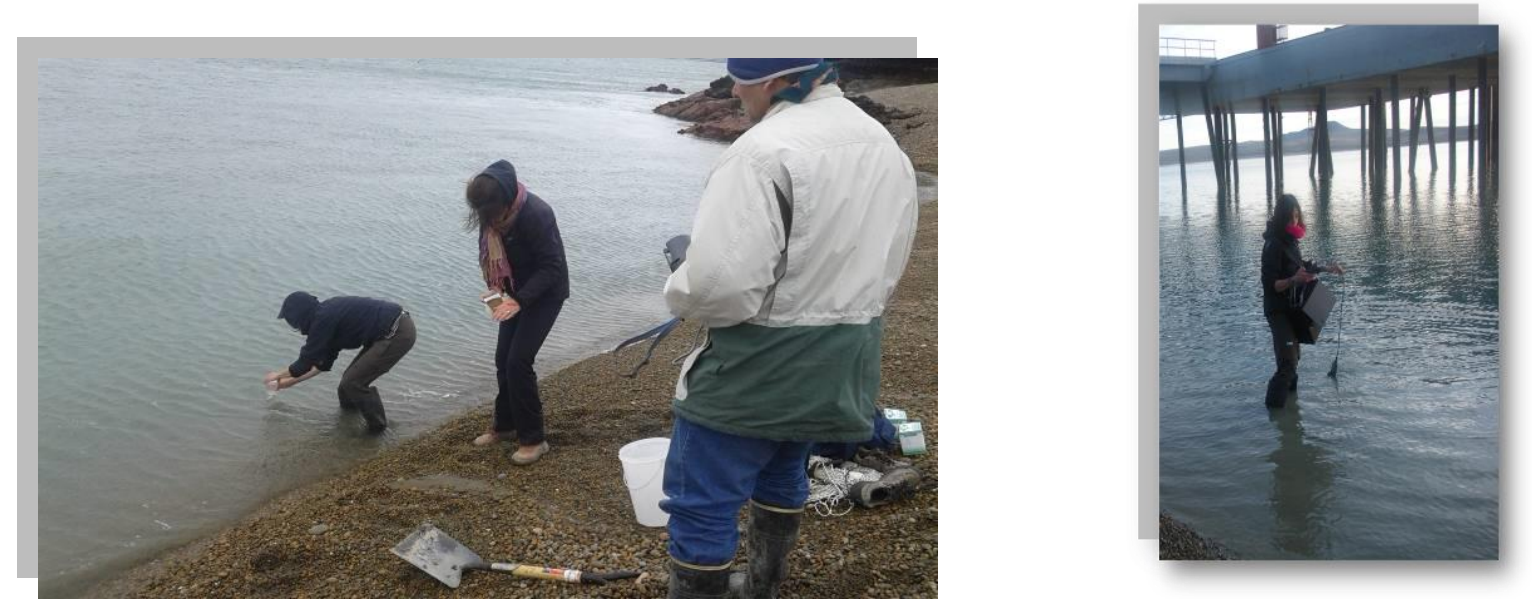

Para la cuantificación de colonias de bacterias se adoptó el método de filtración por membranas. Se utilizaron monitores con filtros de membranas de 0,45 micrones de poros, estériles. Para la determinación de bacterias coliformes totales se filtró un volumen de agua de $100 \mathrm{ml}$ y el medio de cultivo utilizado es Endo Broth. Se cultivaron durante 48 hs a $35+/-$ $1^{\circ} \mathrm{C}$. Luego se cuantificaron ante lupa binocular. El protocolo de muestreo y análisis se basó en los Métodos Normalizados para el análisis de aguas potables y residuales (APHA, 2005).

Figura 3: Determinación de parámetros fisicoquímicos del agua en la estación 25 en canales de marea de la zona de la Cascada.

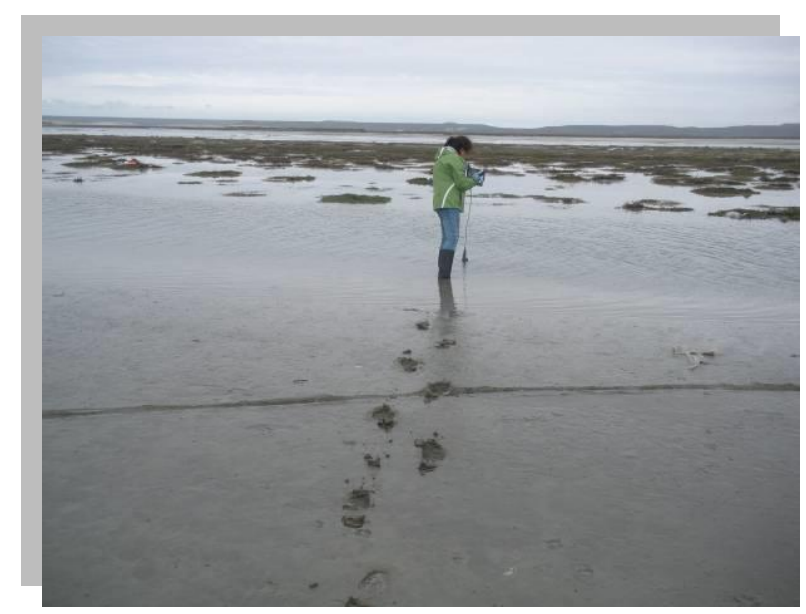




\section{Hidrocarburos}

Las muestras de agua destinadas a la determinación de presencia de hidrocarburos se tomaron en botellas de vidrio color caramelo, capacidad, 1 litro, limpios.

Cuando las muestras se vayan a analizar en lapsos de tiempo mayores $48 \mathrm{hs}$ de su toma, se adicionarán $5 \mathrm{~mL}$ de una solución 1:1 de ácido clorhídrico y agua destilada.

Los envases se prepararon previamente asegurando un apropiado lavado con detergente y agua destilada y finalmente enjuagados con percloroetileno. En caso de no contar con percloroetileno, este paso puede ser obviado siempre y cuando los recipientes estén bien limpios y libres de grasa. Estos envases no deben completarse a desborde, se mantiene la precaución de completar hasta un poco por debajo de la boca de cada frasco (Figura 4).

Para la evaluación de los hidrocarburos se siguieron los lineamientos propuestos para este tipo de análisis según la norma TNRCC 1005 (TNRCC, 2001).

Las determinaciones de las muestras se llevó a cabo en el laboratorio del Grupo de Estudios Ambientales la Universidad Tecnológica Nacional - Facultad Regional Santa Cruz .

Figura 4: En la estación 23, playa Los Instalados sobre la costa oriental de la península, mar abierto, se extrae la muestra para determinar la presencia de hidrocarburos.

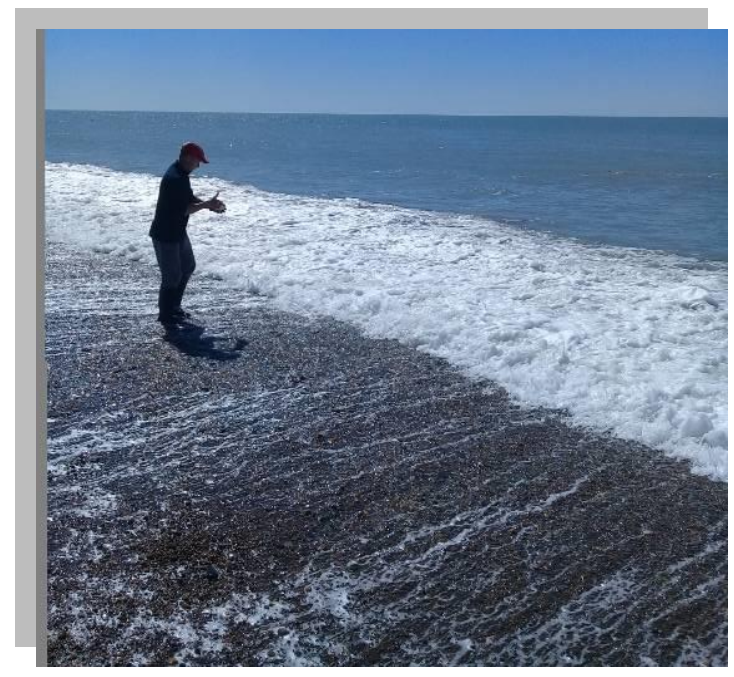

\section{Biota}

Aves

Se realizaron censos de aves marinas y playeras por especie durante 10 minutos en las estaciones de muestreo registrando el número de individuos de todas las especies de aves marinas y playeras presentes en un área rectangular que abarque $500 \mathrm{~m}$ sobre la línea de costa (250 m hacia cada lado del punto de muestreo) y que se extienda $250 \mathrm{~m}$ mar adentro (García y Gómez Laich, 2009). Para la identificación de las aves, se utilizaron las guías de Narosky e Yzurieta (2003) y Couvre y Vidal (2003) .

\section{Resultados, análisis y discusión}

\section{$\underline{\text { Sedimentos }}$}

Concentración de metales pesados 
En el área de estudio, no se ha registrado concentración de Cd y Hg (Gil et al., 1996; Pereyra G. et al, 2015) por lo cual no hay riesgo de contaminación por estos metales.

Otros metales Ausentes en la zona de la BSJ son Bi, Sb, Se, Sn, Ta, Te, W, Ag ya que el valor de las concentraciones están por debajo del límite de detección del método.

Las Figuras 6, 8 y 9 presentan los resultados de las concentraciones totales de los metales pesados registrados para $\mathrm{Cu}, \mathrm{Pb}$ y $\mathrm{Zn}$ en las estaciones seleccionadas (Figura 5).

Figura 5: Vista de la extensa planicie intermareal en marea baja, estación 4, con predominio de fango y arena donde se realizaron los muestreos..

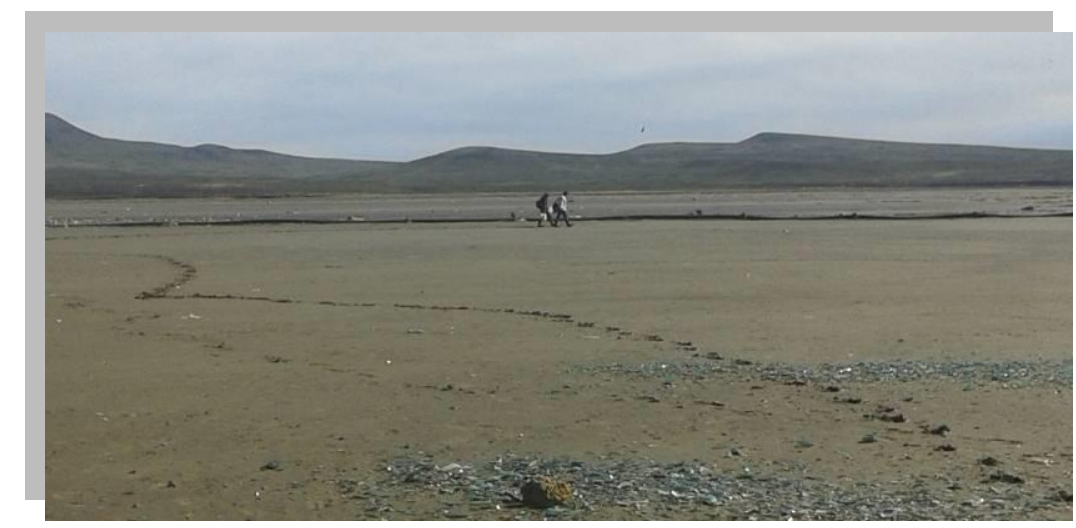

Figura 6: Metales pesados cobre, plomo y zinc medidos en las estaciones de muestreo - E -en la Bahía San Julián

\section{Concentraciones totales}

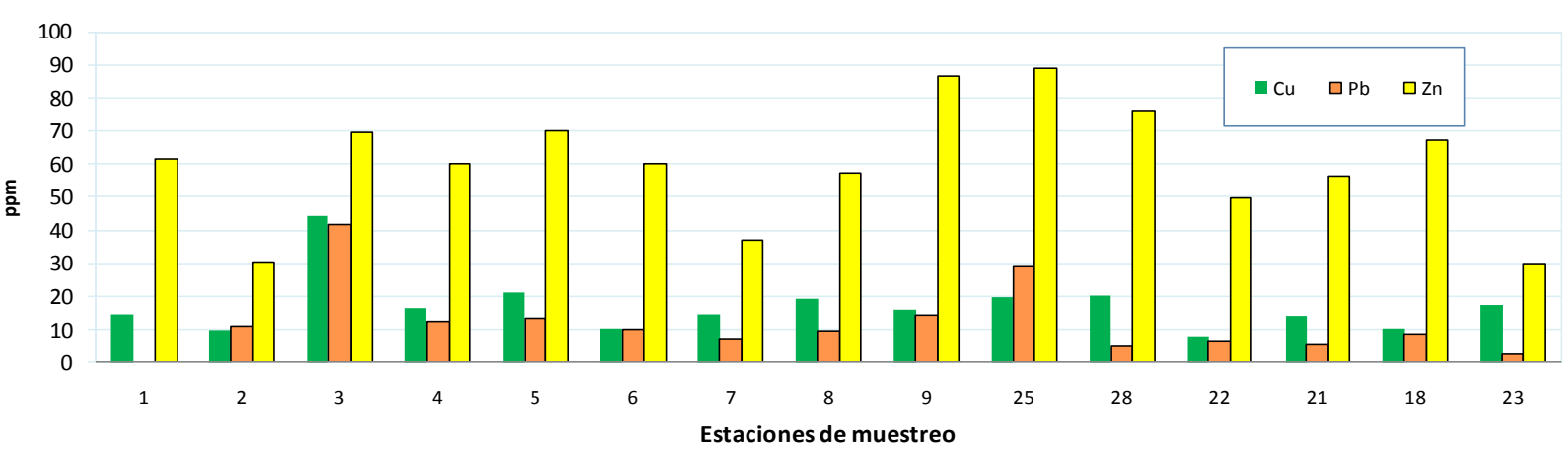

* La estación E3 acusa una concentración relativa mayor en Cu (Figura 5), con respecto a las otras estaciones.

* Las estaciones E3 y E25 muestran tener una concentración relativa mayor en Pb (Figura 6) que las otras estaciones.

* Las estaciones E9, E25 y E28 señalan concentración relativa mayor en Zn (Figura 7) con respecto a las estaciones restantes.

Las causas probables de esta acumulación mayor pueden deberse a características geogénicas tanto sedimentológicas como hidrológicas y antrópicas de acuerdo al siguiente detalle.

La E25 corresponde a un canal de marea cercana a la zona de la Cascada donde históricamente se han depositado residuos sólidos urbanos (basura) y tiene el aporte de descarga de un efluente cloacal.

La E9 está situado en el saco de la BSJ al sur, solo llega el agua en las pleamares vivas o de sicigias que, sumado al déficit hídrico de la zona, la concentración aumenta por la evaporación (Figura 7). 
Figura 7: Aspecto de la zona del saco de la BSJ, estación 9, al fondo de la fotografía

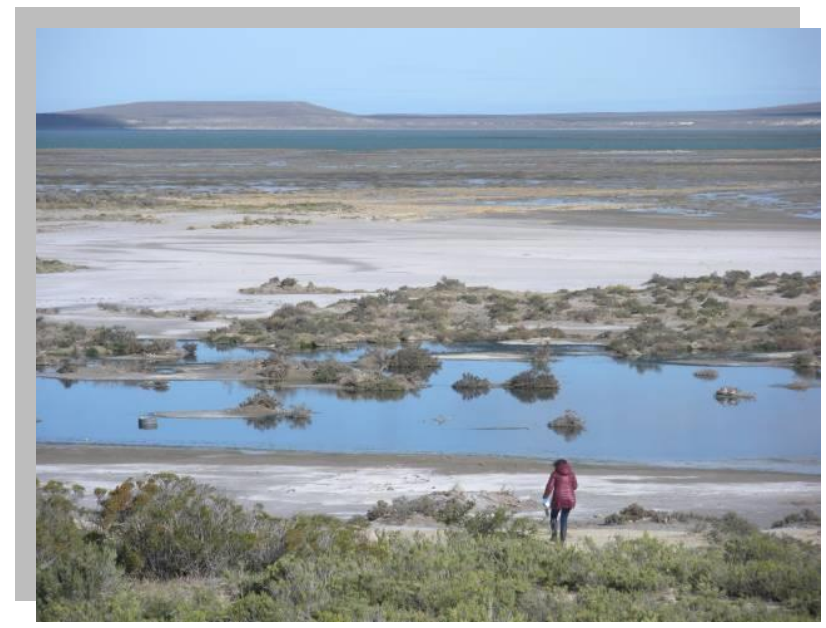

En la E3, paso de la Isla Cormorán, se ha detectado un mayor enriquecimiento relativo de los sedimentos en $\mathrm{Cu}, \mathrm{Pb}$ y $\mathrm{Zn}$.

Figura 8: Concentración de cobre - Cu - en la Bahía San Julián

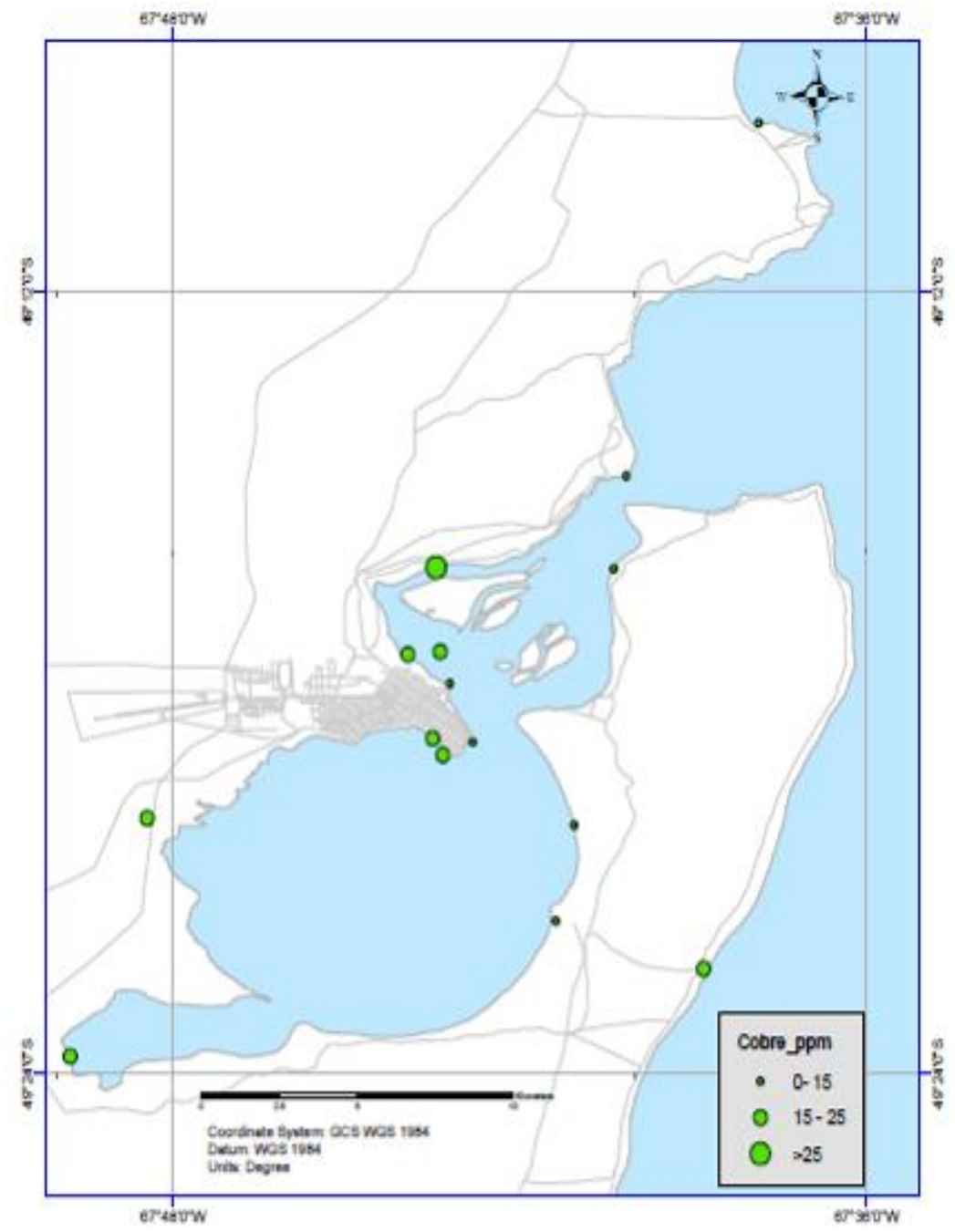

La E3 se sitúa en un canal secundario de la bahía, el cual solo está lleno durante las pleamares ya que en bajamar constituye un paso terrestre entre la isla y la costa occidental de la BSJ. Las 
corrientes de marea, tanto de flujo como de reflujo, son más veloces en el canal principal de la BSJ en tanto que en el sitio donde se sitúa E3 es un tercio de esa velocidad. Bajo estas condiciones, circulación restringida y energía baja del ambiente, el material fino se acumula predominantemente y da como consecuencia una concentración relativa mayor de metales pesados.

La E28 está situada en un arroyo que desemboca en la BSJ - Arroyo Sam - y podría estar relacionado a actividades antrópicas que se desarrollan aguas arriba de la desembocadura.

Figura 9: Concentración de plomo - Pb - en la Bahía San Julián

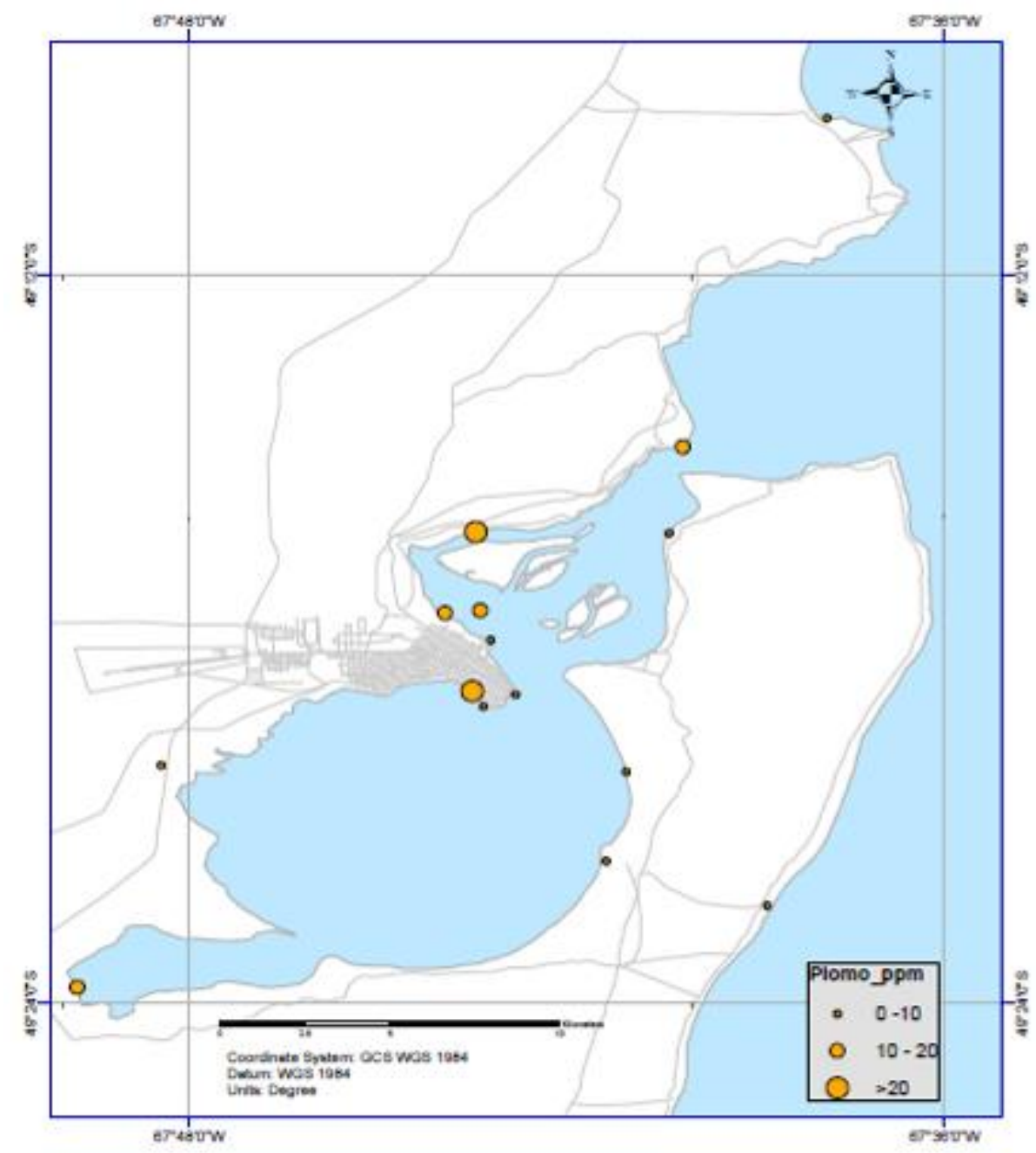

\section{Comparación con la Normativa nacional e internacional}

Las figuras 11, 12 y 13 muestran los valores de las concentraciones de metales pesados $\mathrm{Cu}$, $\mathrm{Pb}$ y $\mathrm{Zn}$ obtenidos respectivamente y se los relaciona con la normativa vigente nacional e internacional.

De la observación de los gráficos se infiere que los valores registrados de $\mathrm{Cu}, \mathrm{Pb}$ y $\mathrm{Zn}$ están por debajo de los límites normados lo que permite afirmar que no constituyen riesgo de contaminación y que permiten la preservación de la vida acuática es decir indica ausencia de daños permanentes a las comunidades bentónicas (Long et al., 1995). Se destaca que para el $\mathrm{Cu}$, en la E3 el valor se encuentra apenas por encima del ERB (Efectos de Rango Bajo) que 
indica que las concentraciones por debajo de este nivel, rara vez se producen efectos adversos sobre la vida acuática.

Figura 10: Concentración de zinc - Zn - en la Bahía San Julián

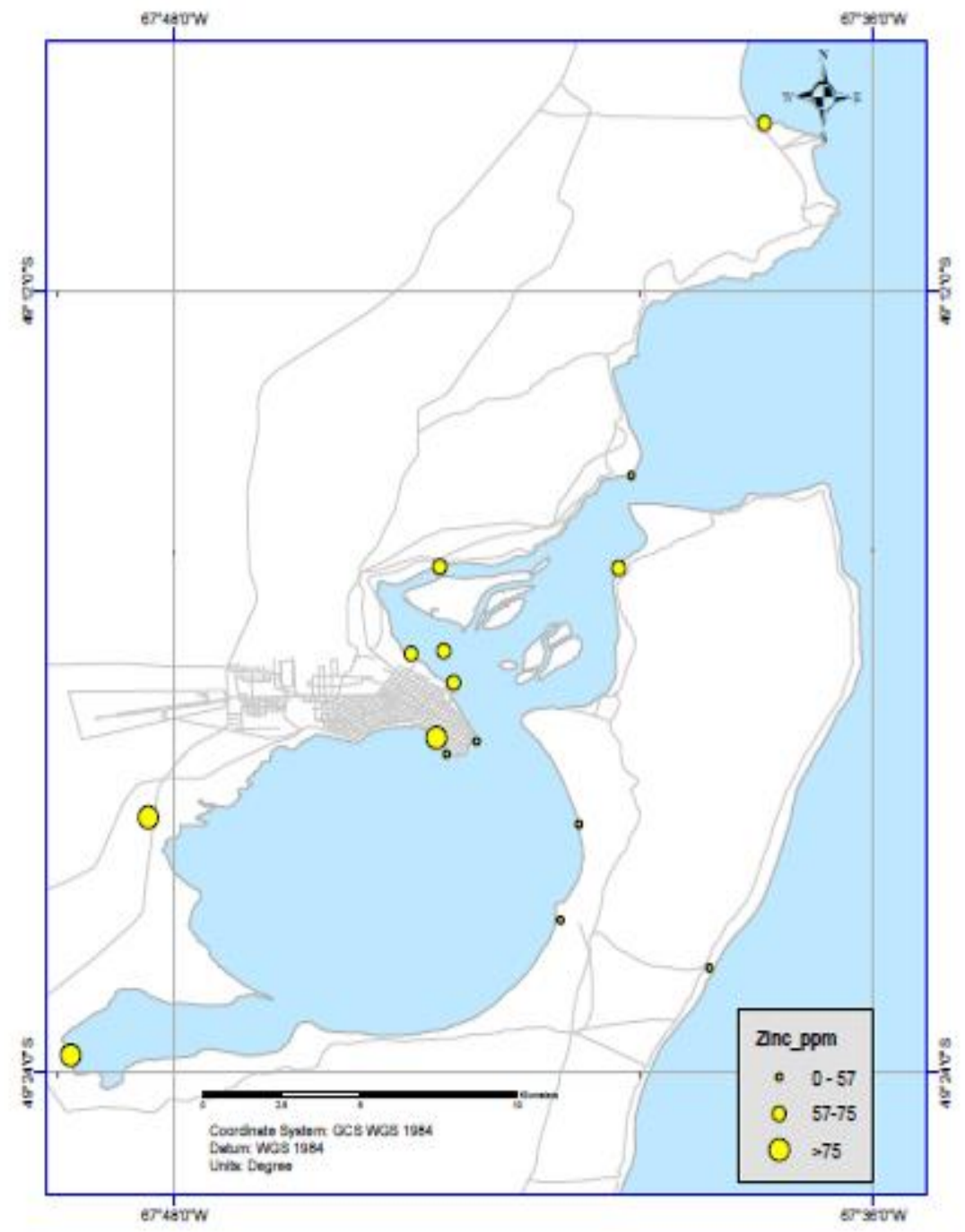

\section{Índices}

Evaluación ambiental de los sedimentos marinos. Índice de Geoacumulación:

Para el cálculo del IGeo, se tomó como

A. "Bn" a los valores de referencia definidos a nivel global Average Shales de Turekian y Wedepohl (1961) para compararlo con los datos obtenidos en el resto de las estaciones.

B. "Bn" a los valores preindustriales, correspondiente a ambientes no contaminados de la E2 - Punta Peña - situada al norte de la BSJ para compararlo con los datos obtenidos en el resto de las estaciones. 
Figura 11: Los valores de concentración de Cobre encontrados en la BSJ en relación a la normativa nacional e internacional

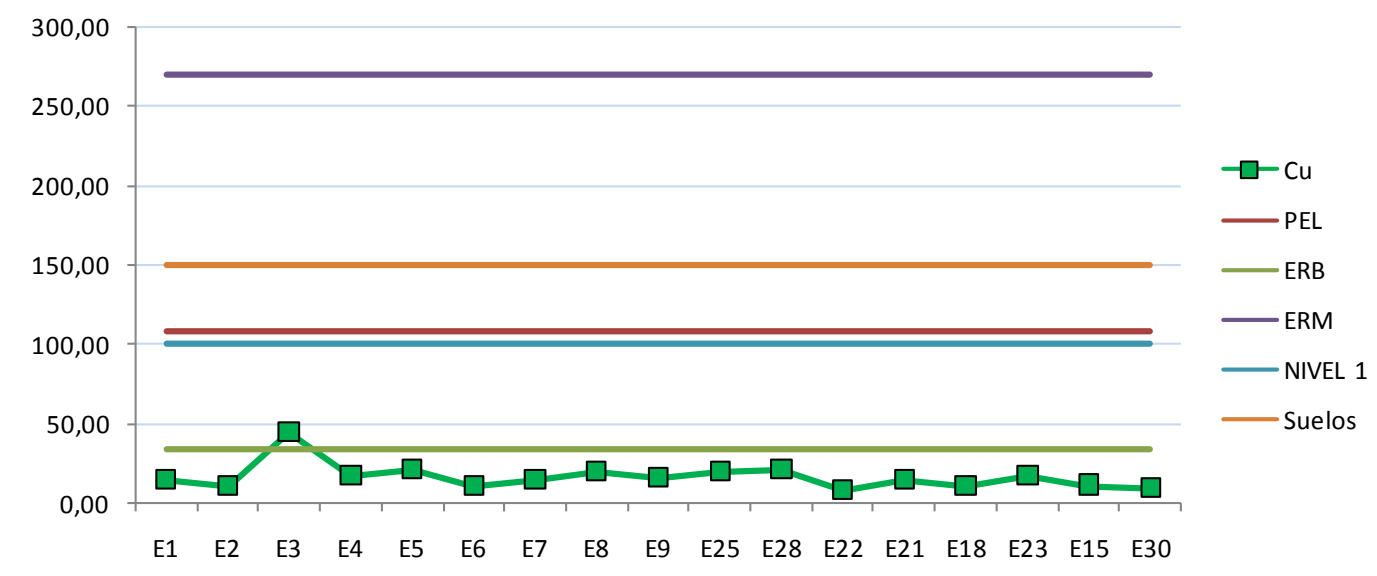

Figura 12: Los valores de concentración de Plomo encontrados en la BSJ en relación a la normativa nacional e internacional

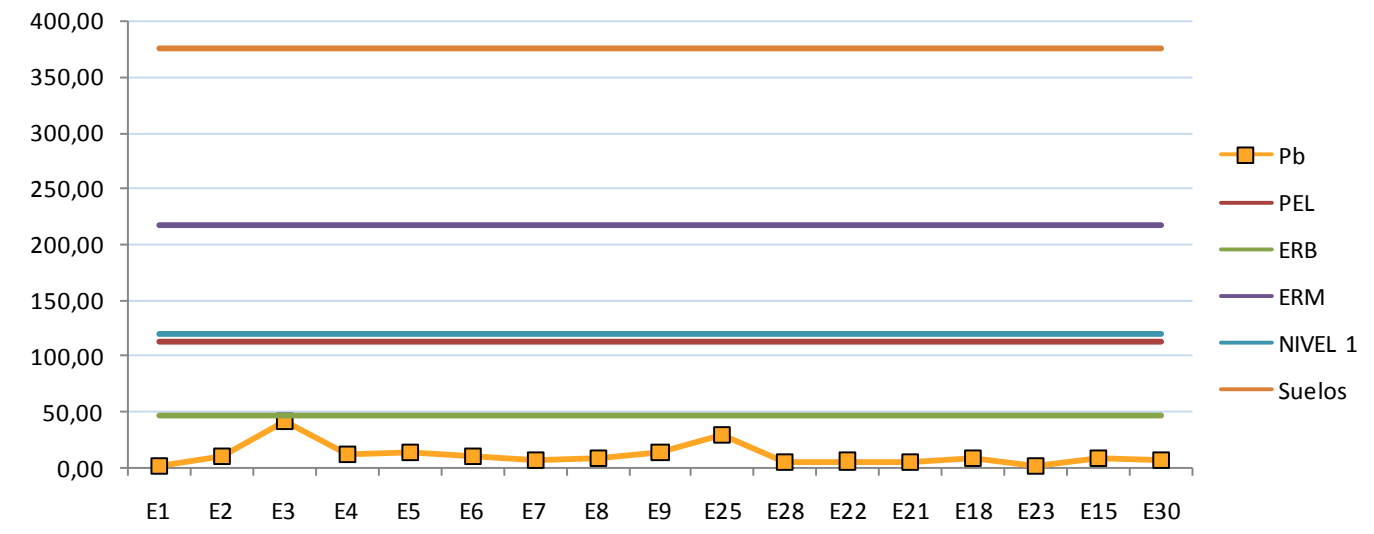

Figura 13: Los valores de concentración de Zinc encontrados en la BSJ en relación a la normativa nacional e internacional

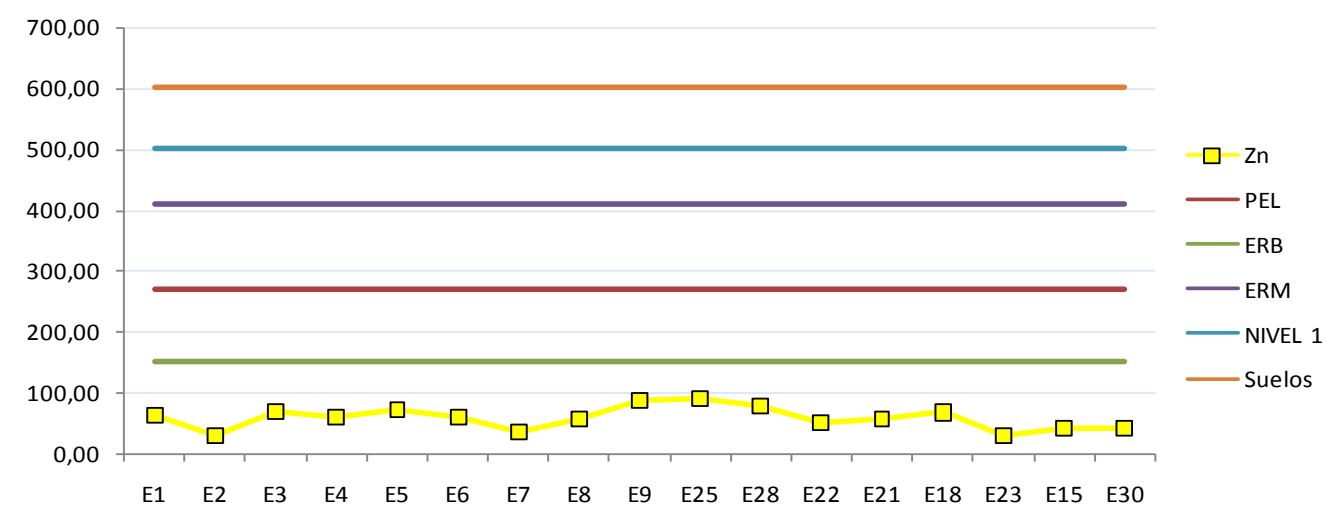

El Indice de Geoacumulación, calculado en relación a niveles basales de formaciones geológicas tradicionales y en relación a un ambiente similar pero sin intervención antrópica presentó algunas diferencias como se aprecia en las Figuras 14 y 15. 
Figura 14: Distribución espacial del IGeo según Turekian y Wedepohl

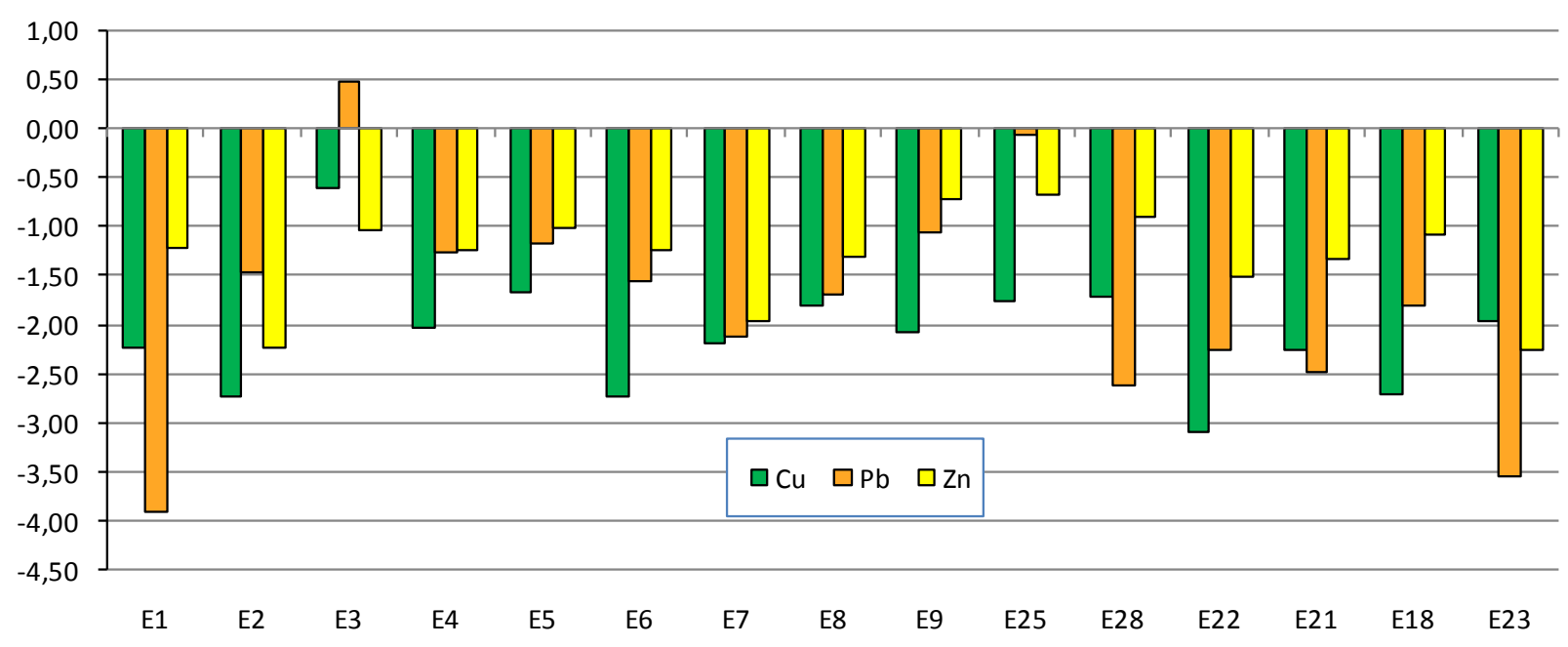

- En el primer caso (Fig. 14), los resultados sugieren que la mayoría de las estaciones son de Clase 0, "No contaminadas" para $\mathrm{Cu}, \mathrm{Pb}$ y $\mathrm{Zn}$, comparando con las lutitas (Average shales) de Turekian y Wedepohl de la bibliografía general. Sólo el IGeo para $\mathrm{Pb}$ en $\mathrm{E} 3$ es de Clase 1 (No contaminado a moderadamente contaminado) de acuerdo a la clasificación de Müller (1979).

Analizando el gráfico de la Figura 15, se infiere que:

- El IGeo para el Cobre: La E3, Paso de la Isla Cormorán, presenta contaminación moderada (Clase 2); seis estaciones no evidencian contaminación (Clase 0) y las siete restantes alcanzan la Clase 1 - No contaminado a moderadamente contaminado.

- El IGeo para el Plomo: E3 es de Clase 2 (contaminación moderada), E25 tiene Clase 1 (No contaminado a moderadamente contaminado). Las restantes doce estaciones no acusan contaminación (Clase 0 ).

- El IGeo para el Zinc: Doce estaciones son de Clase 1 y solo dos de las restantes no están contaminadas (Clase 0).

Figura 15: Distribución geoespacial del IGeo según los valores preindustriales tomados de la estación 2 - Punta Peña.

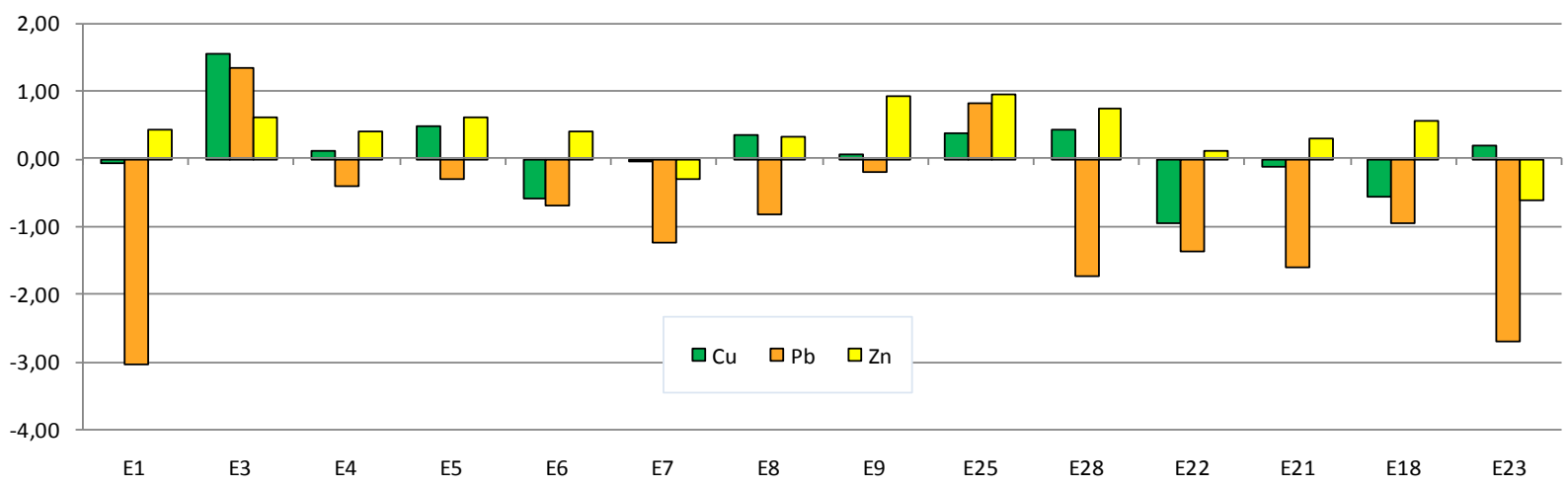

Es necesario considerar la posibilidad que los niveles utilizados en este trabajo (a falta de otros más efectivos), no permitan aplicar de manera correcta este índice.

Diversos autores discuten el uso de niveles preindustriales para evaluar el grado de enriquecimiento de metales pesados en sedimentos marinos (Buccolieri et al., 2006; Fang et al., 2009; Calderón y Valdés, 2012). 
Estos autores por lo general concluyen que si bien los valores de referencia definidos a nivel global (Average Shales) permiten una aproximación al real impacto de la actividad antrópica sobre las características geoquímicas de los sedimentos, es necesario definir localmente dichos niveles, ya sea mediante el establecimiento de concentraciones en zonas sin intervención antrópica o, en la medida de lo posible, definir valores preindustriales dentro de secuencias sedimentarias que permitan realizar reconstrucciones paleoambientales.

\section{Índice de contaminación Urbano Industrial - CUI -}

Los valores mayores de CUI se encuentran en la margen occidental de la BSJ donde la actividad humana está más desarrollada y su impacto ambiental consecuente (Fig. 16, 17 y 18).

Figura 16: En las cercanías del basural, sobre la planicie intermareal de la estación 5 se observan la cantidad de bolsas de plástico que impactan el ambiente litoral.

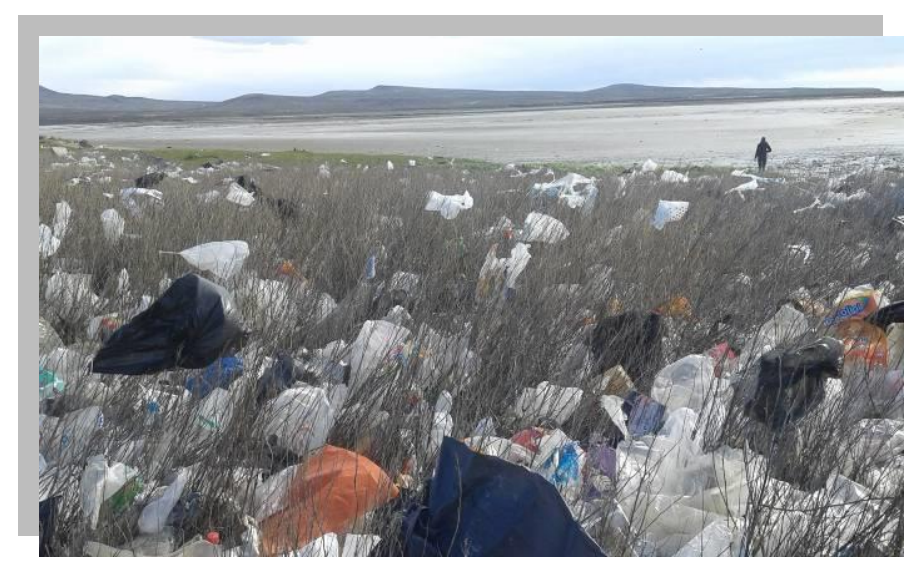

Figura 17: Aspecto de un lugar impactado en la planicie intermareal cercana a la estación 20 en la zona de la descarga del efluente cloacal.

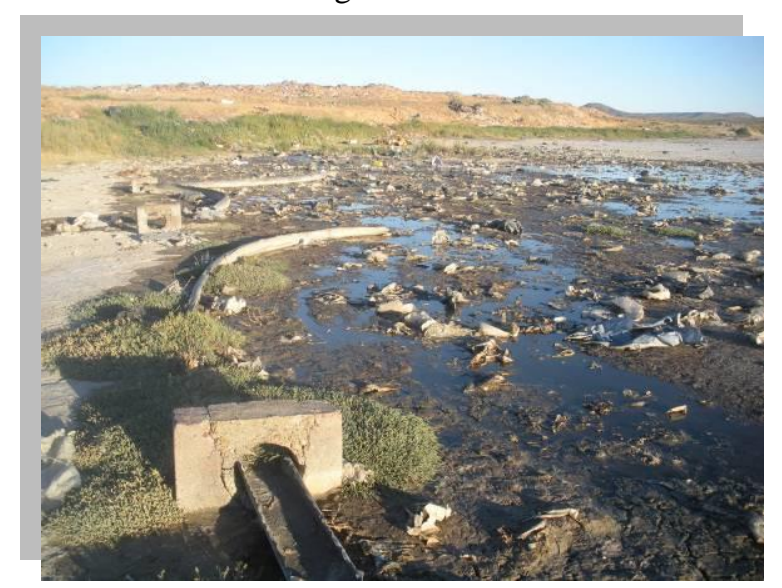


Figura 18: Valores del Índice de contaminación urbano industrial - CUI - en la BSJ.

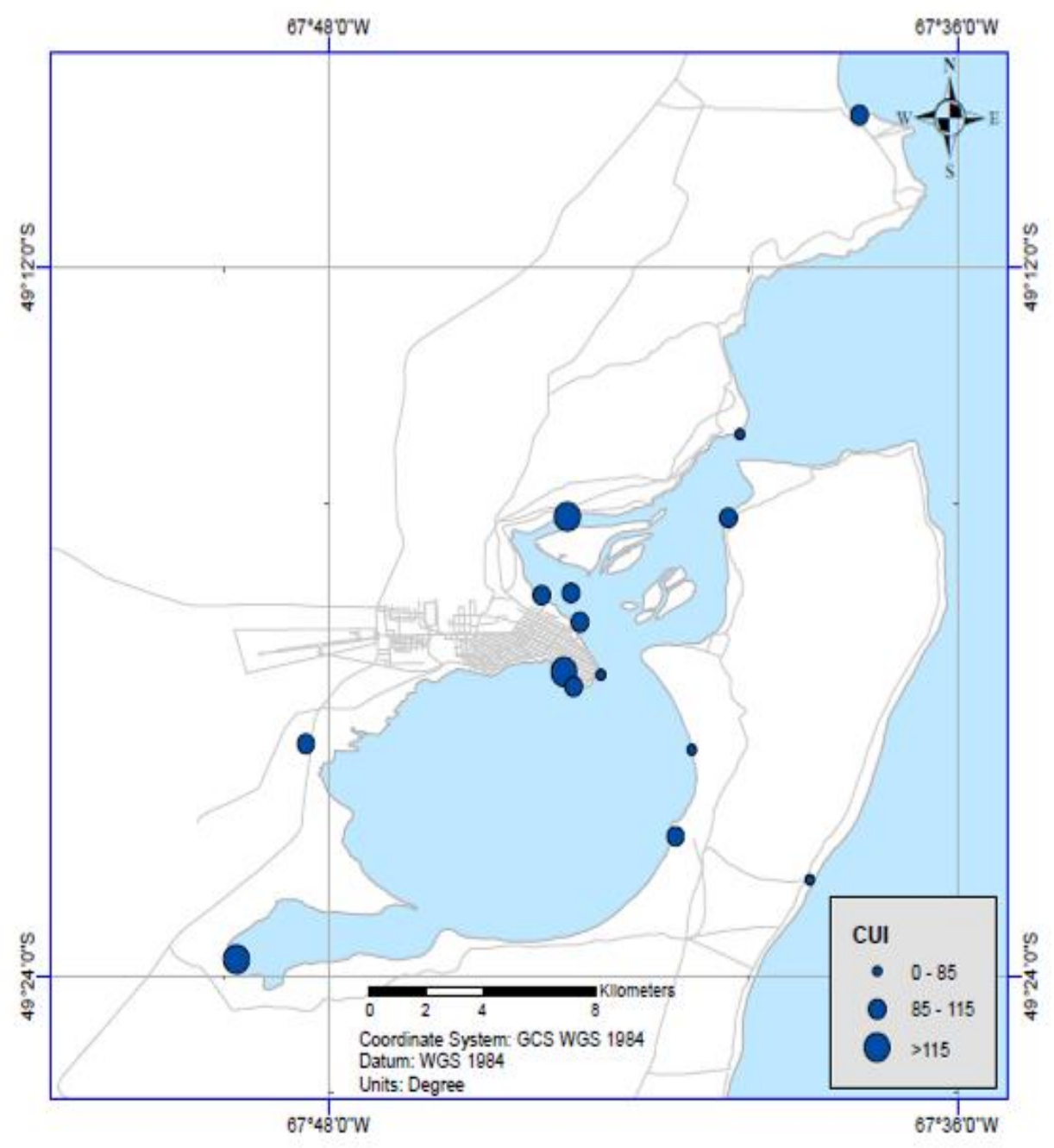

\section{$\underline{\text { Aguas }}$}

Caracterización de las propiedades físicas del agua

A partir de las variables físicas relevadas in situ en cada sitio de muestreo, se dan a conocer el valor de cada parámetro. El pH promedio medido es 8.23. Las temperaturas registradas durante los muestreos, presentan un mínimo de $6{ }^{\circ} \mathrm{C}$ en otoño y un máximo de $14.5^{\circ} \mathrm{C}$ en primavera. La salinidad muestra poca variabilidad que se mantiene entre un 3 a 3,5\% en todos los sitios y en las dos estaciones del año. La conductividad promedio es de 58.78 $\mathrm{uS} / \mathrm{cm}$.

\section{Muestreo bacteriológico}

En todas las estaciones en las cuales se realizó el muestreo bacteriológico se pudo comprobar la existencia de bacterias coliformes totales (Figura 20). 
Tabla 7: Valores de bacterias Coliformes Totales por estación de muestreo.

\begin{tabular}{|c|l|c|c|}
\hline Estación & \multicolumn{1}{|c|}{ Lugares } & $\begin{array}{c}\text { Máximo valor de } \\
\text { Coliformes totales } \\
\mathbf{2 0 1 5} / \mathbf{2 0 1 6} \\
\text { (UFC/100 ml) }\end{array}$ & $\begin{array}{c}\text { Máximo valor de } \\
\text { Coliformes totales } \\
\mathbf{2 0 1 7 - 2 0 1 8 .} \\
\text { (UFC/100 ml) }\end{array}$ \\
\hline 23 & Playa Los Instalados & 48.5 & 50 \\
\hline 2 & Punta Peña & 121 & 50 \\
\hline 3 & Paso de la Isla Cormorán & 14 & 97 \\
\hline 4 & Efluente Marea baja - Intermareal fango-arenoso & 34.000 & s/d \\
\hline 5 & Efluente Marea Alta & 3.500 & s/d \\
\hline 20 & Cámara de descarga efluente cloacal- Planta & 4.200 .000 & 840.000 .000 \\
\hline 6 & Tratamiento & 50 & 150 \\
\hline 7 & Punta Caldera - muelle & 269.5 & 160 \\
\hline 8 & Club Náutico & 114 & 74 \\
\hline 18 & Caldera baja & 38.5 & 39 \\
\hline 24 & Efluente Cascada - Calle Alberdi & 37.000 & 18.600 \\
\hline 25 & Canal marea Cascada & 1.100 & 650 \\
\hline 21 & Rincón - Península & $\mathrm{s} / \mathrm{d}$ & 286 \\
\hline 22 & Frente al Pueblo - Península & $\mathrm{s} / \mathrm{d}$ & 28 \\
\hline
\end{tabular}

En la Tabla 7 y la Fig. 21 se muestran los registros máximos de bacterias Coliformes Totales que se determinaron en los muestreos realizados durante el período 2015-2018.

Se toman los valores máximos de dos años de muestreo (2015 y 2016) y se compara con los máximos de 2017 y 2018 esperando alguna relación, la cual no se ha visto reflejada. En color rojo se indican los valores que sobrepasan el límite establecido en las normativas.

Figura 19: Muestreo de la estación 20, cámara de descarga del efluente cloacal.

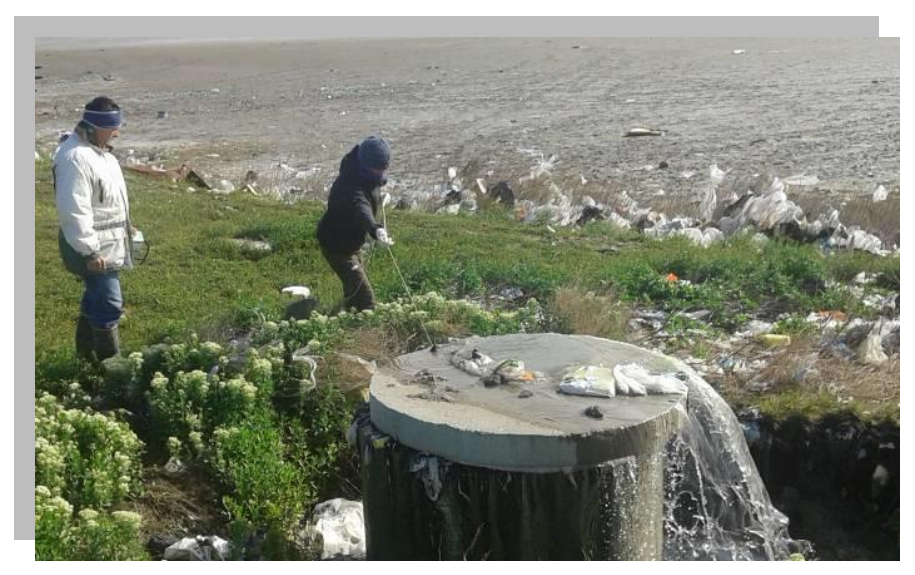

El sitio de liberación del efluente indica una clara ausencia de tratamiento e incremento de la carga bacteriana de un período a otro. La capacidad de amortiguación de la bahía se comprueba con los valores de los demás sitios (Figura 21) los cuales están en rangos aptos según las normativas vigentes.

Figura 20: En el laboratorio de la UASJ, se realizan los análisis bacteriológicos del agua de la BSJ. A la derecha, los monitores obtenidos para ser analizados 

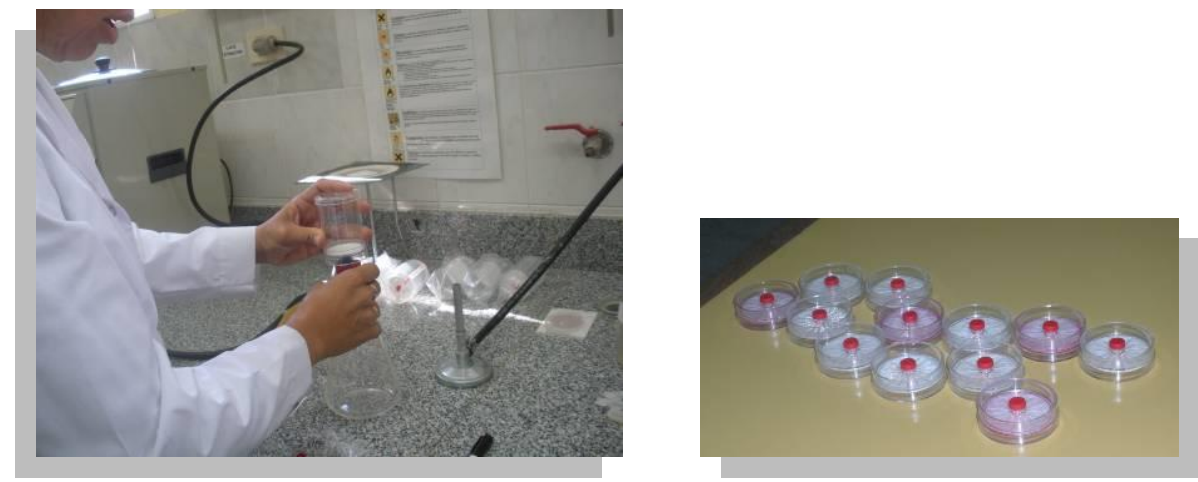

\section{Hidrocarburos totales}

Los hidrocarburos totales medidos en las estaciones muestreadas están Ausentes, es decir que se encuentran por debajo del límite de detección del método, salvo en el vertido cloacal, cuyo valor registrado es de $5 \mathrm{~g} / \mathrm{l}$. Al momento presente, los hidrocarburos no representan peligro de contaminación.

\section{Biota}

Aves

En este ecosistema complejo se hallan colonias de aves marinas, principalmente colonias reproductivas de gaviotas cocineras (Larus dominicanus), pingüinos (Spheniscus magellanicus) y cormoranes (Phalacrocorax albiventer, Ph. magellanicus, Phalacrocorax olivaceus).

Figura 22: La Cascada, estación 8, sitio recreativo de la localidad con diferentes especies de aves: cisne coscoroba (Coscoroba coscoroba) y flamenco austral (Phoenicopterus chilensis).
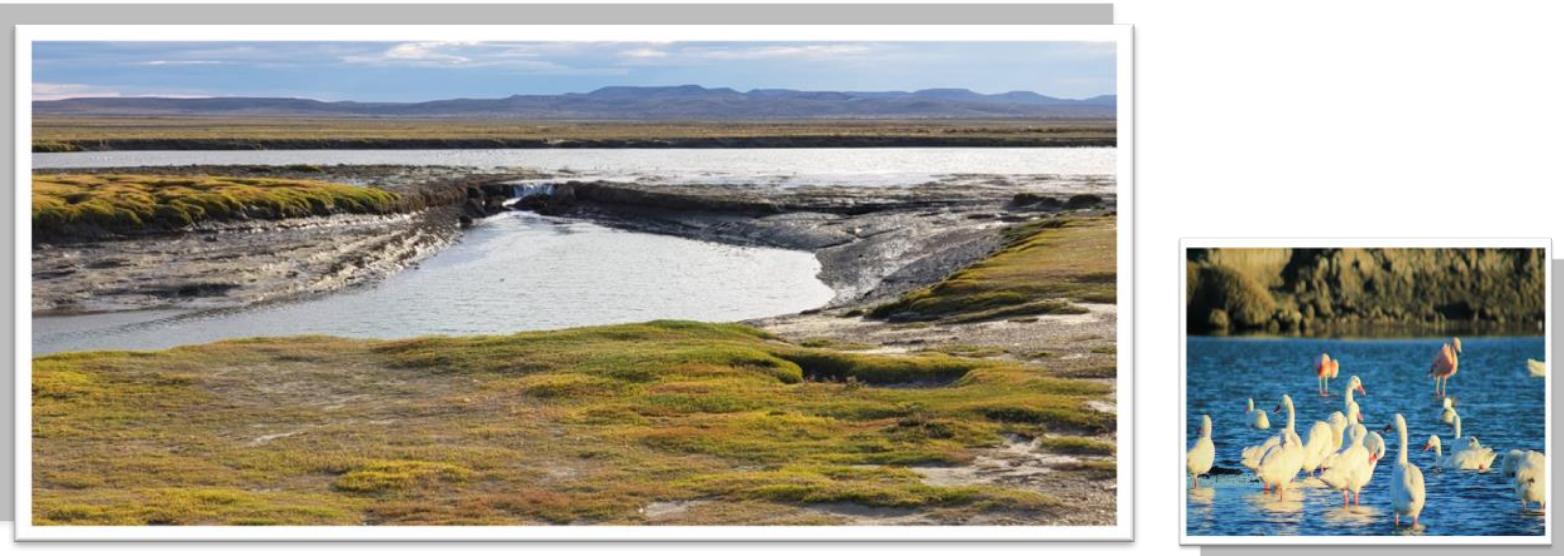
Figura 21: Estaciones con los valores de bacterias Coliformes Totales - BSJ

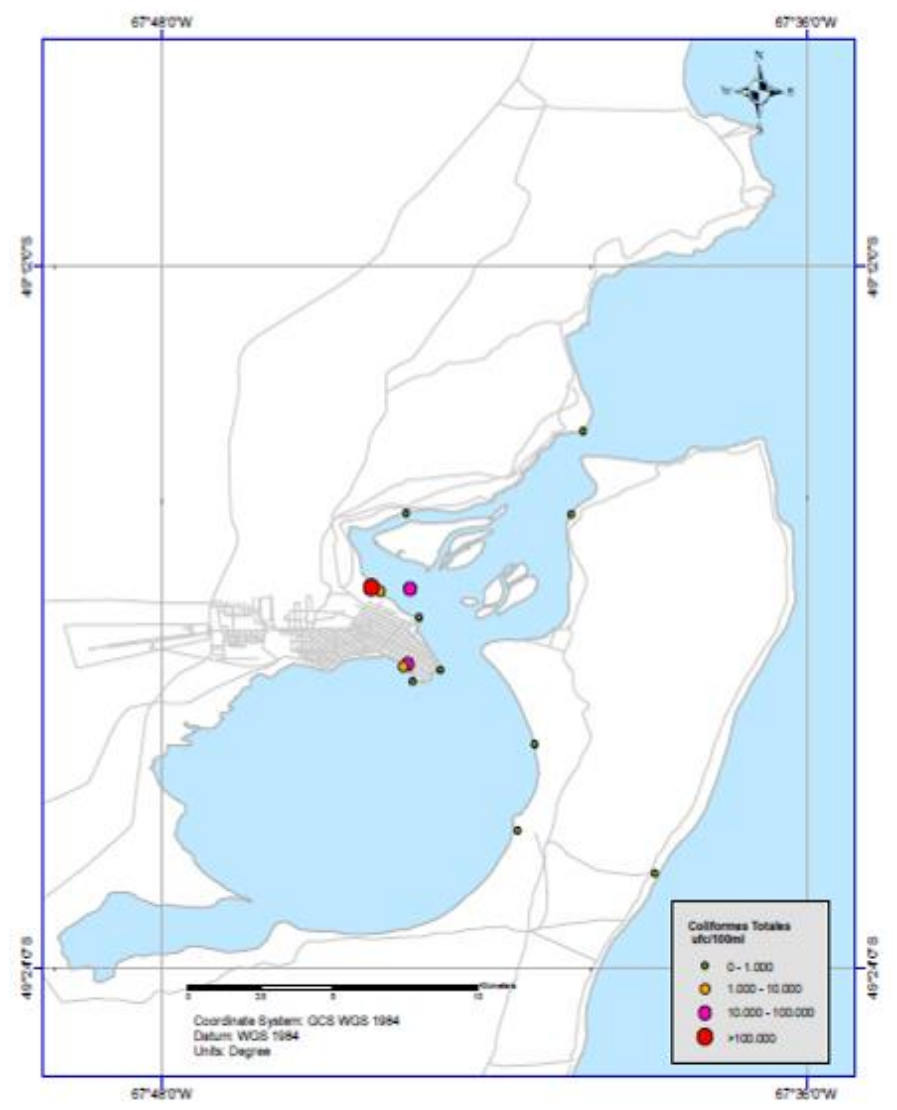

Algunos ejemplares de cisne coscoroba (Coscoroba coscoroba) y flamenco austral (Phoenicopterus chilensis) son frecuentes en la zona de la Cascada (Figura 22)

En cuanto a las aves, se ha observado que los disturbios influyen sobre la diversidad de aves en cada sitio, ya que se pone en evidencia un gradiente basado en la disminución en la riqueza y un aumento en la abundancia, como ocurre en la zona de los efluentes cloacales (E3), especialmente en aquellas especies generalistas y omnívoras (Larus dominicanus).

\section{CONCLUSIONES}

$\checkmark$ La concentración de los metales pesados $\mathrm{Cu}, \mathrm{Pb}$ y $\mathrm{Zn}$ en los sedimentos mareales no representa problemas de contaminación ambiental en la bahía ya que están por debajo de los rangos permitidos por la normativa vigente de referencia.

$\checkmark$ Los metales pesados Ausentes en la zona de la BSJ son Cd, Hg, Bi, Sb, Se, Sn, Ta, Te, W, Ag debido a que los valores de concentración registrados están por debajo del límite de detección del método.

$\checkmark$ La calidad de los sedimentos estudiados basado en la normativa ambiental tanto nacional como internacional consultadas no constituyen peligro para la vida acuática marina ni para el ambiente.

$\checkmark$ Los valores de IGeo representan ambientes "no contaminados" para las estaciones de la BSJ si se los compara con niveles basales de formaciones geológicas tradicionales shales - . 
$\checkmark$ Los valores mayores de CUI se encuentran en la margen occidental de la BSJ y coincide con la mayor actividad antrópica que se desarrolla en la zona.

$\checkmark$ Los resultados bacteriológicos en el sitio de liberación de los efluentes cloacales (E 20) superan ampliamente el límite establecido en la Ley $N^{\circ} 2658$ de Santa Cruz, como cuerpos receptores En la estación E4 y E24, los niveles están por encima de los límites normados y solo es apto para la vida acuática (Ley 1503, Decreto 2099/77). En tanto que en E5 y E25 se mantiene elevado para la aptitud de uso recreativo. En los restantes sitios los valores están por debajo de los son aceptables para cuerpos acuáticos de uso recreativo, navegación deportiva y pesca y para la protección de la vida acuática.

$\checkmark$ Los hidrocarburos totales medidos en agua no representan riesgo de contaminación ya que están por debajo del límite de detección del método.

$\checkmark$ Los sitios disturbados se caracterizan por un gradiente en el cual la riqueza de especies de aves disminuye en pos de un aumento en la abundancia, como ocurre en la zona de los efluentes cloacales, donde especialmente se concentran aquellas especies generalistas y omnívoras (Larus dominicanus).

\section{CONSIDERACIONES Y RECOMENDACIONES}

Por el momento, la concentración de los metales pesados $\mathrm{Cu}, \mathrm{Pb}$ y $\mathrm{Zn}$ estudiados en este trabajo no representan problemas de contaminación ambiental en la bahía ni peligro para la vida acuática.

Es importante indicar que existen diferencias en los rangos definidos por las normativas, debido a las metodologías utilizadas para establecer los valores de referencia. Esto es esperable toda vez que la heterogeneidad espacial de los ambientes naturales que se pretende proteger hace aconsejable definir concentraciones de determinados compuestos de acuerdo a las características propias de dicho ambiente, más que replicar normativas de otras regiones geográficas. Las diferencias encontradas en el uso de normas de calidad de sedimentos y concentraciones de base para el cálculo de índices de calidad ambiental demuestran la necesidad de establecer una propuesta de normativa sobre la base de las características propias de estos ambientes costeros.

Los resultados del IGeo fueron diferentes dependiendo de los niveles de concentración base de metales utilizados.

Por su parte, el estudio microbiológico de las aguas requiere especial atención, ya que los altos valores encontrados en el vertido cloacal y las estaciones receptoras circundantes son indicadores de alteración del sistema natural. El ambiente de la BSJ demuestra una alta capacidad de dilución de la carga bacteriana a medida que se distancia del punto de vertido.

Por otro lado, la comparación entre dos períodos no muestra relación alguna, se debe profundizar el estudio de la dinámica espacio-temporal de la microbiología de las aguas de la Bahía.

Por lo antes expuesto, es necesario continuar con el monitoreo sistemático de los parámetros analizados a lo largo del tiempo para identificar, evaluar y remediar eventuales alteraciones del ambiente natural.

\section{AGRADECIMIENTOS}

Este trabajo forma parte de los proyectos de investigación PI 29D/063 y PI 29D/075 financiados por la Universidad Nacional de la Patagonia Austral. Además, ha recibido aportes 
del proyecto de extensión "Diagnóstico ambiental de Puerto San Julián y su entorno natural" financiado por la Fundación Agencia de Desarrollo de Puerto San Julián.

Asimismo, se agradece la colaboración del Dr. Juan Pablo Martin, Lic. Santiago Torres y Lic. Pablo Moscoso. Todos los proyectos fueron desarrollados en la Unidad Académica San Julián.

\section{LISTAS DE REFERENCIAS}

AMAT INFANTE, P., PIERRA CONDE, A., CASALS BLET, I. y VÁZQUEZ ABELLA, D. 2002. Estudio de la contaminación por metales pesados en sedimentos y ostiones de la bahía de Manzanillo, Cuba. Comunicación Técnica. Revista de la Sociedad Química de México, Vol. 46, Núm. 4 Pp.357-361

APHA (2005) Standard methods for the examination of water and waste water, 21st edn. American Public Health Association, Washington, DC.

BECKER, Y. y COLLM, N. 2015. Relevamiento preliminar de aves costeras en zona de "La Cascada" de Puerto San Julián, Santa Cruz, Argentina. XVI Reunión Argentina de Ornitología. La Plata, Buenos Aires, Argentina

BOERSMA, PD. REBSTOCK, GA. FRERE, E. y MOORE, S.E. 2009. Following the fish: penguins and productivity in the South Atlantic. Ecological Monographs, 79(1): 5976.

BUCCOLIERI A., G. BUCCOLIERI, N. CARDELLICCHIO, A. DELL'ATTI, A. DI LEO y A. MACI. 2006. Heavy metals in marine sediments of Taranto Gulf (Ionian Sea, Southern Italy). Mar. Chem., 99: 227-235.

CALDERÓN, C y VALDÉS, J. 2012 Contenido de metales en sedimentos y organismos bentónicos de la bahía San Jorge, Antofagasta, Chile. Revista de Biología Marina y Oceanografía Vol. 47, $\mathrm{N}^{\circ} 1$ : 121-133, abril

CCME, 2002, Canadian Council of Ministers of the Environment, 2002, Canadian Environmental Quality Guidelines, Winnipeg Canada.

CENTRO DE ESTUDIOS Y EXPERIMENTACIÓN DE OBRAS PUBLICAS. 1994. CEDEX. Recomendaciones para la gestión del material dragado en los puertos españoles. Ministerio de Obras Públicas, Transportes y Medio Ambiente, Madrid.

COLLM, N. GANDINI, P. y FRERE, E. 2008. Relevamiento poblacional de las aves marinas de la Bahía de San Julián. XII Reunión Argentina de Ornitología, San Martín de los Andes. 99p. Congreso Nacional de Cartografía. Instituto Geográfico Militar. Buenos Aires. p 72-80.

COUVRE, E. VIDAL y C. 2003. Aves de Patagonia, Tierra del Fuego y Península Antártica. Editorial Fantástico Sur, Chile. 656 pp.

DE GREGORI, I.; PINOCHET, H.; ARANCIBIA, M. y VIDAL, A., (1996). Grain-size effect of trace metals distribution in sediments from two coastal areas of Chile. Bull. Environ. Contam. Toxic Pollut., 57, 163-170.

ESTEVES, J. L. y P. C. GONZÁLEZ. 2007. Relevamiento de la situación ambiental urbana en la zona costera patagónica. Proyecto GEF-PNUD ARG/02/G31 "Consolidación e Implementación del Plan de manejo de la Zona Costera Patagónica para la Conservación de la Biodiversidad" Agencia Implementadora: Fundación Patagonia Natural

FANG, T., J. LI, H. FENG \& H. CHEN. 2009. Distribution and contamination of trace metals in surface sediments of the East China Sea. Mar. Environ. Res., 68: 178-187. 
FRERE, E. Y GANDINI, P. 1998. Capítulo 8: Distribución reproductiva y abundancia de las aves marinas de Santa Cruz. Parte II: de Bahía Laura a Punta Dungeness. En: Atlas de la distribución reproductiva de Aves Marinas en el Litoral Patagónico

GARCIA, A. 2000. El origen de las localidades de Santa Cruz y algunos aspectos de su desarrollo: San Julián. P. 602-612; En: El Gran libro de Santa Cruz. Godoy C. (Director), Tomo 1, 652p. Ed. ALFA-Milenio, Madrid.

GARCÍA, G O. y GÓMEZ LAICH, A. 2007. Abundancia y riqueza específica en un ensamble de aves marinas y costeras del sudeste de la Provincia de Buenos Aires, Argentina. El Hornero 22(1):9-16.

GIL, M; M. HARVEY, M. COMMENDATORE, J. C. COLOMBO \& J. L. ESTEVES. 1996. Evaluación de la contaminación por hidrocarburos y metales en la zona costera patagónica. Informe Técnico 21.Plan de Manejo Integrado de la Zona Costera Patagónica GEF / PNUD WCS / FPN

KOKOT, R; SCAVUZZO, V; COLLM, N y WALKER, P. 2013. Guía Temática de San Julián: Geológica Geología Costera Área la Localidad de Puerto San Julián. Universidad Nacional de la Patagonia Austral, Río Gallegos NPA, San Julián. 50 pp.

LONG, E., D. MACDONALD, S. SMITH y F. CALDER. 1995. Incidence of adverse biological effects within ranges of chemical concentrations in marine and estuarine sediments. Environ. Manage., 19: 81-97.

MARCO LEGAL DE LA PROVINCIA DE CHUBUT. 1977. Ley Nº 1503. Decreto 2099/77 Protección de las Aguas y de la Atmósfera 10/11/1977

MARCO LEGAL DE LA PROVINCIA DE SANTA CRUZ. 2003. Ley Nº 2658. Evaluación de impacto ambiental. Decreto 7/06.

MILLONES, A. y FRERE, E. 2012. Environmental Factors Affecting the Distribution of the Red-legged Cormorant in Argentina: A Regional Scale Approach. Waterbirds 35(2): 230-238.

MÜLLER G. 1979. Schwermetalle in den sedimenten des Rheins - Veranderungen seit 1971. Umschau 79: 778-783

NAROSKY, T. y YZURIETA. D. 2010. Guía para la identificación de las aves de Argentina y Uruguay. Edición de Oro. 16 a Edición. Vázquez Mazzini Editores, Buenos Aires. $432 \mathrm{pp}$.

PANZA, J. L. y M.V. IRIGOYEN 1994. Hoja geológica 4969 - IV "Puerto San Julián", provincia de Santa Cruz. Dir. Nac. del Serv. Geol. Sec. Minería. BsAs.

PAPAKOSTIDIS, G.; GRIMANIS, A.P. y D. ZAFIROPOULOS. 1975.Heavy metals in sediments from the Athens sewage outfall area. Marine Pollution Bulletin Vol. 6, Issue 9, Pg. 129-144.

PEREYRA GINESTAR, B. R., SCAVUZZO, V., MOSCARDI, C. y TOMADIN, P. 2017. Caracterización ambiental de la bahía San Julián, Santa Cruz. XX Congreso Geológico Argentino. ST $\mathrm{N}^{\circ} 15$ "Riesgo geológico y geología ambiental y urbana". San Miguel de Tucumán.

PEREYRA GINESTAR, B. y SCAVUZZO, V. 2016. Índices de geoacumulación de metales trazas en los sedimentos submareales de la Bahía San Julián, Santa Cruz, Argentina. Actas 1:80 XI E-ICES - International Center for Earth Sciences., Mendoza.

PEREYRA GINESTAR, B.R., BECKER, Y., SCAVUZZO, V., COLLM, N.S, MOSCARDI, C.A., TOMADIN, P, STORNIOLO, S., ARRIETA, LB, SCHITTNER, C.D. y SANCHEZ, G. 2015. Estudio de la situación ambiental de la Bahía San Julián y su zona de influencia, provincia de Santa Cruz. IX Jornadas Nacionales de Ciencias del Mar, Ushuaia, 293 pp.

PEREYRA GINESTAR, B.R., SCAVUZZO, V., MOSCARDI, C.A.; COLLM, N.S., TOMADIN, P., STORNIOLO, S. , ARRIETA, L. y BECKER, Y.A. 2016. Estudio de 
la situación ambiental de la bahía San Julián, a través de la medición de la calidad de agua y sedimentos, Santa Cruz. IV EIUNPA, Caleta Olivia, Santa Cruz.

PROPATAGONIA (UNPA-UARG) - SUBSECRETARÍA DE PLANEAMIENTO Y DE FUNCIÓN PÚBLICA (MSGG). 2007. San Julián Piensa San Julián 2007-2020. Ordenamiento del territorio en Puerto San Julián. Plan Participativo de Desarrollo Sustentable para San Julián y su Área de Influencia. Modelo Territorial Actual. Tomo I. $102 \mathrm{p}$.

SCAVUZZO, V y PEREYRA GINESTAR, B. 2016. Aspectos geomorfológicos de la Bahía San Julián y alrededores procesados digitalmente con el software SOPI. XI Encuentro E-ICES - International Center for Earth Sciences -. Malarguie, Mendoza, Argentina.

SCHWEITZER A. 2007. Plan de Ordenamiento y Desarrollo Territorial, Santa Cruz 2016. Primera Etapa del Plan Estratégico Territorial Provincial. CFI - Subsecretaría de Planeamiento y de la Función Pública (MSGG); 80p.

SCHWEITZER A., MONELOS L., CÁCERES A., MARTINEZ LLANESA D., LÜRBE M., VIDART A. y DIAZ BORIS G. 2006. Prediagnóstico situacional y prospectivo orientado al desarrollo de un plan regulador para la localidad de Puerto San Julián.

SOTO, J. 2004. Clima. En Guía geográfica interactiva de la provincia de Santa Cruz. Editores: González y Rial. Convenio INTA- Provincia de Santa Cruz- Universidad Nacional de La Patagonia Austral. Santa Cruz, Argentina.

SZEFER, P., KUSAK, A. y SZEFER, K. (1998): Evaluation of the anthropogenic influx of metallic pollutants into Puck Bay, southern Baltic. Applied Geochemistry, 13 , 293304.

TAGLIORETTE, A. y LOSANO, P. 1996. Informe técnico 24 Estudio de la demanda turística en las ciudades de la costa patagónica. Fundación Patagónica Natural (F.P.N.) y Wildlife Conservation. International (W.C.S.) ISSN No $0328-462 X$.

TNRCC - Texas Natural Resource Conservation Commission. 2001. Method 1005: Total petroleum hydrocarbons.

YORIO, P y G. HARRIS. 1997. Distribución reproductiva de aves marinas y costeras coloniales en Patagonia: Relevamiento aéreo Bahía Blanca - Cabo Vírgenes, noviembre 1990. Informe Técnico $\mathrm{N}^{\circ}$ 29. Plan de Manejo integrado de la Zona Costera Patagónica (Puerto Madryn). 31 pp.

TUREKIAN, K.K. y WEDEPOHL, K.H. (1961). Distribution of the Elements in some major units of the Earth's crust. Geological Society of America, Bulletin 72:

ZAIXSO, H. 2007. Estudio de base para la gestión integrada de la bahía de San Julián. Informe Técnico. $802 \mathrm{pp}$. 